\title{
A multicriteria Master Planning DSS for a sustainable humanitarian supply chain
}

\author{
Laura Laguna-Salvadó ${ }^{1}$. Matthieu Lauras ${ }^{1}$. \\ Uche Okongwu ${ }^{2}$. Tina Comes ${ }^{3,4}$
}

\begin{abstract}
Humanitarian supply chains (HSCs) contribute significantly to achieving effective and rapid responses to natural and man-made disasters. Though humanitarian organizations have during the last decades made considerable efforts to improve the response to crises in terms of effectiveness and efficiency, HSCs are still faced with so many challenges, one of which is the incorporation of sustainability dimensions (economic, social and environmental) in the management of their supply chains. In the literature, some authors have highlighted that the planning and achievement of sustainability performance objectives in humanitarian operations is hindered by the lack of decision support systems (DSS). Therefore, this paper proposes a multi-objective Master Planning DSS for managing sustainable HSCs. This Master Planning DSS includes: (1) the definition of a set of metrics for measuring the performance of a sustainable HSC; (2) an algorithm to solve the multi-objective problem; and (3) a Master Planning mathematical model to support the tactical planning of the sustainable HSC. Using the information gathered from field research and the literature, an illustrative numerical example is presented to demonstrate the implementation and utility of the proposed DSS. The results show that the order in which the three sustainability dimensions (economic, social
\end{abstract}

Uche Okongwu

u.okongwu@tbs-education.fr

Laura Laguna-Salvadó

llagunas@mines-albi.fr

Matthieu Lauras

matthieu.lauras@mines-albi.fr

Tina Comes

t.comes@tudelft.nl

1 Department of Industrial Engineering, University of Toulouse, IMT Mines Albi, Route de Teillet, 81013 Albi Cedex 9, France

2 Department of Information, Operations and Management Sciences, Toulouse Business School, 20 Boulevard Lascrosses, 31000 Toulouse, France

3 Department of ICT, University of Agder, 4879 Grimstad, Norway

4 Department of Multi-Actor Systems, Delft University of Technology, Delft, The Netherlands 
and environmental) are prioritized has some impact on the performance measures. Therefore, it is important to fix a tolerance that would enable to obtain an acceptable balance (tradeoff) between the three sustainability objectives, in line with the prioritization choice of the decision maker.

Keywords Disaster relief operations · Humanitarian supply chain - Sustainable supply chain $\cdot$ Sustainability $\cdot$ Master Planning $\cdot$ Multi-objective decision support system

\section{Introduction}

Humanitarian supply chains (HSCs) are designed to support the distribution of emergency goods to alleviate the suffering of people affected by natural and man-made disasters. Though Humanitarian Organizations (HOs) have observed that logistics and supply chain performance is key to a successful operation (Van Wassenhove 2006), the performance of HSCs has not been systematically measured, probably because measuring "alleviation of human suffering" is intangible (Balcik and Beamon 2008). Also, in contrast with commercial supply chains where performance is measured using a multicriteria approach, HSCs focus on effectiveness as the main performance driver or value (Widera et al. 2013). Moreover, given that HOs have a project management approach where the response to each disaster constitutes a project, humanitarian efforts have for a long time been focused more on the response phase (with a very reactive behaviour) and much less on the preparedness (and planning) phase. As a result, the lack of preparedness and planning-developing strategies and coordinating HSC operations - has led to inefficiencies and misallocation of resources (Jahre 2008). Today, measuring the performance of HSCs has become very necessary and important (Santarelli et al. 2015) for three major reasons.

Firstly, the effective and reactive (and often inefficient) behaviour of HOs has been put to test by competition for funds. Given the continuously increasing gap between the needs of humanitarian activities and the availability of funds, HOs must compete to gain and retain public and private donors who finance their operations (Balcik and Beamon 2008). Therefore, they need to measure, manage and improve the performance of their supply chains with the aim of developing critical success factors that would constitute a competitive advantage.

Secondly, not only do donors ask more and more for greater transparency and accountability, they also have become less and less tolerant of inefficiencies (Balcik et al. 2010). As a result, HSC managers have started paying attention to efficiency (in addition to effectiveness) due also to the fact that the management of HSCs has been identified as the most expensive part of relief operations (Van Wassenhove 2006). At the beginning of the twenty-first century, HOs such as the International Federation of the Red Cross and Red Crescent (IFRC) or the World Food Program (WFP) made some strategic design choices that aimed to improve both effectiveness and efficiency. For example, the deployment of a network of prepositioned stocks enabled to improve effectiveness (in terms of reduction of response times) and reduce acquisition costs thanks to the management of centralized inventories and long term-relationships with suppliers (Jahre 2008). Also, in the humanitarian operations management literature, many optimization models use this two-dimensional (effectiveness/efficiency) view of HSC performance measurement (Beamon and Kotleba 2006; Ozbay and Ozguven 2007; Ye and Liu 2013). Gualandris et al. (2015) argue that competitive advantages are possible by addressing various stakeholders' expectations. 
Thirdly, today the biggest challenges for humanity are ending poverty, protecting the planet, and ensuring prosperity for all (United Nations 2016a). In their introductory statement of a special issue on energy economics and climate policy modelling, Huang et al. (2017) state that "Climate change is one of the biggest medium to long term risks to global development, $\ldots$, and it is predicted to have severe consequences across such sectors as ecosystems, agriculture, industry, commerce, residences, and transportation." The inclusion of 17 sustainable development goals in the 2030 Agenda for Sustainable Development (United Nations 2016b) buttresses the fact that developing a sustainable global economy is paramount in the world of today. Moreover, as global citizens, people are becoming more and more sensitive to and concerned about the impact of their actions and choices on the environment and society. Many authors have argued and/or observed that the rising awareness of environmental and social sustainability issues, and their integration into the management of supply chains, constitute factors that foster competitiveness (Gopalakrishnan et al. 2012; Markley and Davis 2007; Maryniak 2017). In the 1990s, Hart (1997) had already reported that, in the commercial sector, sustainability had been identified as one of the biggest opportunities for doing business. Consequently, the current evolution of the donors' expectations suggests that sustainability will in the coming years be considered more and more to be a competitive advantage for HOs that are seeking for funds. In a recent study, Dubey and Gunasekaran (2016) asserted that, in future, both commercial and humanitarian supply chains will be guided by sustainable development and ecological balance.

Despite these observations (consumers' and society's awareness, and donors' need for transparency and accountability), sustainability parameters have not been adequately and sufficiently taken into consideration in measuring the performance of HSCs (Haavisto and Goentzel 2015). Today, there is need for decision makers to evaluate the impact of their decisions with respect to sustainability performance objectives (Gualandris et al. 2015). In the humanitarian sector, this practice would enhance not only the improvement of HSC processes but also the anticipation of the impact of future actions on performance (Day et al. 2012). We note that in this sector the inclusion of the concept of sustainability in the management process is quite recent, and decision makers do not have concrete metrics and tools for measuring sustainability performance (Yadav and Barve 2016). Several authors have called for more research to integrate sustainability into humanitarian decision-making (Haavisto and Kovács 2014; Klumpp et al. 2015; Kunz and Gold 2017). Therefore, in this paper, we propose a set of sustainability performance measures and associated metrics.

The effective use of metrics can only be guaranteed by incorporating them in formal planning and management systems. But the lack of structured planning processes in HSCs (Haavisto and Kovács 2014), which are typically supported by decision support systems (DSS), hinders the management ex-ante of the impact of both strategic and operational decisions. Thus, developing a DSS adapted to the HSC may not only help to improve the performance of planning processes (Abidi et al. 2014), but will also enable decision makers to take into consideration sustainability performance objectives. Structured planning processes are necessary to align decisions with the expected performance objectives. DSSs for planning are not commonly used for managing HSCs. Previous researchers have highlighted that misalignment with field specificities and lack of trust are the main reasons for the difficulties of transferring information technology from the commercial sector to humanitarian settings (Abidi et al. 2014). Using a functional model specifically created for HSCs may facilitate the development of appropriate IT systems (Blecken 2010).

Blecken (2010) proposed a model (see Fig. 1) where the standard processes of the HSC are defined as: assessment, procurement, warehousing and transport. In the HSC literature, researchers have used mainly Operational Research (OR) approaches to support the plan- 


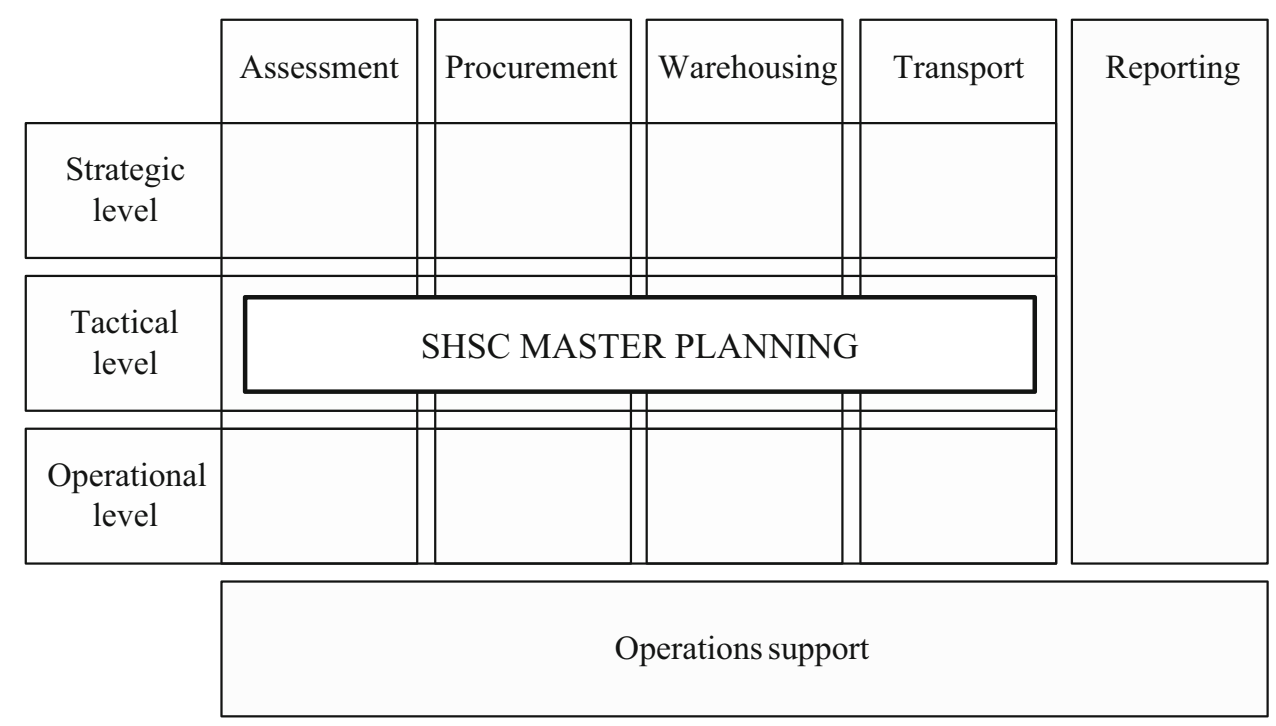

Fig. 1 SHSC Master Planning Module in the Blecken (2010) reference task model

ning of the standard processes of the HSC (Jabbour et al. 2017; Kovács and Spens 2011; Van Wassenhove 2006). This covers mostly the strategic and operational levels of the HSC planning matrix. In practice, the tactical planning level (Master Planning and Demand Planning) of the HSC is less developed due to the segmented nature of the management of disaster responses within HOs. HSC managers conceive each disaster response as a single supply chain solution instead of building a tactical planning system that aggregates the HO's network, in parallel with other on-going operations. In this paper, we propose a tactical level planning system for the HSC.

In a nutshell, until now, the main objectives of HSC managers have been to improve competitiveness by simply having an effective management of supply flows while minimizing costs. With the continuous development of the sustainability paradigm, social and environmental performance measures need to be added to the performance measurement dashboard of HSCs. But, the lack of structured planning processes, concrete sustainability measurement tools and DSSs jeopardize the enhancement of sustainable operations.

This paper aims to contribute to filling this gap by setting the basis for a DSS to help decision makers in planning humanitarian operations in a way as to achieve acceptable performance levels in all three dimensions of sustainability (economic, social and environmental) in addition to effectiveness. Our proposal is three-dimensional: (1) defining a set of sustainability performance measures and associated metrics, (2) developing a Multi-Objective Optimization Method, (3) developing a mathematical model for tactical planning decisions in an HSC. These three components of our work would contribute to improving the performance of HSC processes in terms of sustainability.

To illustrate our proposal, we will use the case of the International Federation of Red Cross and Red Crescent (IFRC). We have chosen the IFRC because of its very active engagement in the American continent, which is a good example for studies that discuss recurrent disasters. The crises affecting America are mostly natural disasters with recurrent patterns such as El Niño (Charvériat 2000). These small- and medium-scale crises constitute a very high percentage of emergency interventions by HOs (Vargas Florez et al. 2015). Moreover, the logistic network of the IFRC, and more precisely the American \& Caribbean Regional Logistic Unit, offers specialized HSC services (i.e. warehousing and procurement) to the humanitarian community and deploys a "sub-regional" network of warehouses that are positioned close to 
the risk areas. Though a lot of effort has been made, the economic sustainability to maintain these structures is still a challenge and there is room for improvement in terms of efficiency and effectiveness. Also, there is no effective tactical planning system. So, regional operations are managed "ad-hoc", with a weak global vision of the operations within the network, and without concrete consideration of sustainability performance.

The rest of this paper is organised as follows. Firstly, we will define the key terms in Sect. 2, before a literature review in Sect. 3. Secondly, we will present our research methodology in Sect. 4. Thirdly, in Sect. 5 we will present our proposal, which is composed of three complementary components that aim to support the decision-making process in a sustainable HSC. Fourthly, an illustrative numerical case (based on the IFRC upstream HSC) will be presented and discussed in Sect. 6 to demonstrate the relevance of the proposed model. Finally, in Sect. 7 we will draw some conclusions that will include managerial implications, perspectives for further research and limitations.

\section{Definitions}

For a better understanding of the model that is proposed in this paper, there is need to clarify the definition of the key terms that constitute the core of our study. These key terms are sustainable humanitarian supply chain, sustainability performance measurement and Master Planning.

\subsection{Sustainable humanitarian supply chain}

We can understand what a sustainable humanitarian supply chain (SHSC) is by asking three questions:

- What is sustainability?

- What is a sustainable supply chain?

- What is a humanitarian supply chain?

\subsubsection{Sustainability}

The word sustainability may have different meanings in different country contexts and fields of study (Filho 2000), but in the business management literature, the most widely quoted definition is that found in the Brundtland Report (1987) where it is defined as: "development that meets the need of the present without compromising the ability of future generations to meet their own needs". While authors such as Kiewiet and Vos (2007) consider this to be the definition of "sustainability", others (Wilson 2003; Presley et al. 2007) refer to it as "sustainable development". In this paper, we will simply use the term sustainability. The Brundtland's definition being too general and abstract, we will adopt Pojasek's (2012) operationalized definition, which considers sustainability as "the capability of an organization to transparently manage its responsibilities for environmental stewardship, social wellbeing, and economic prosperity over the long-term while being held accountable to its stakeholders."

Whatever the way this term is defined, it is generally agreed that the performance of a sustainable organization is based on the "triple-bottom-line" (TBL) approach constituted by the economic, social and environmental components of sustainable development (Elkington 1998; Hemming et al. 2004; Robins 2006). 


\subsubsection{Sustainable supply chain (SSC)}

One of the most cited definitions of a supply chain is that given by Christopher (1992), which states that "a supply chain is the network of organizations that are involved, through upstream and downstream linkages, in the different processes and activities that produce value in the form of products and services delivered to the ultimate consumer." Though a sustainable supply chain can be considered logically and intuitively as the application of sustainability to a supply chain, Kleindorfer et al. (2005) extended it by defining sustainable supply chains using the concept of closed-loop supply chains and triple bottom line thinking. The definition of Carter and Rogers (2008) further adds transparent integration of an organization's social, environmental and economic goals. Considering that twenty-first century organizations are pressured by different stakeholders to incorporate sustainability goals into the management of their supply chains, Seuring and Müller (2008) defined sustainable supply chain management (SSCM) as "the management of materials, information and capital flows as well as cooperation among companies along the supply chain while integrating goals from all three dimensions of sustainable development-economic, social and environmental, which are derived from customer and stakeholder requirements."

In this paper, we are going to adopt the above definition. However, we need to draw the readers" attention to the fact that in the literature the terms "sustainable supply chain" (SSC) and "green supply chain" (GSC) are sometimes used interchangeably and ambiguously. The interchangeable and ambiguous use of these two terms can be observed in Jabbour et al. (2016) where, while investigating barriers to the adoption of green operational practices by Brazilian companies, they reviewed works that studied SSC in China. They also cited Schrettle et al. (2014) who claim that green operations management is the main driver of sustainable companies. Before drawing a conclusion, let us look at two opposing definitions from the literature. According to Seuring and Müller (2008), GSC management is defined as "the management of materials, information and capital flows as well as cooperation among companies along the supply chain while taking into account goals from all three dimensions of sustainable development, i.e. economic, social and environmental, which are derived from customer and stakeholder requirements". On the other hand, Carter and Rogers (2008) proposed a definition which includes only the environmental dimension. They defined GSC management as "a process of integrating environmental dimensions with the traditional supply chain network". This ambiguity is also evidenced in the study done by Sarkis et al. (2011) where some of the reviewed papers associated the word "sustainable" almost exclusively to the word "green". Considering that the areas of SSC and GSC are overlapping with very thin boundaries separating them, Singh and Trivedi (2016) even went to the extent of using both terms (green and sustainable) in their paper titled "Sustainable green supply chain management: trends and current practices".

Clarifying the difference between SSC and GSC is not the aim of this paper. Therefore, we refer our readers to one of the most recent and exhaustive literature reviews done by Dubey et al. (2017b), where it can be seen that GSCs have to do with the integration of environmental dimensions with the traditional supply chain network while SSCs embrace not only environmental performance measures along with the profit/loss (economic) statement but also includes social performance measures. This view is supported by the call from Gunasekaran et al. (2016) to do more research on this issue; they stated that "Sustainability should not only be viewed from the perspective of economic and environment, but social implications must be incorporated in supply chain network design." We argue that, for the sake of clarity, the term "green" should be restricted to the environmental dimension of sustainability, while the term "sustainability" should be used when studying the three dimensions. Our argument 
is in line with Ashby et al. (2012) who established that SSC management is an extension of GSC management since the latter only considers the environmental aspect of a sustainable business. We also refer our readers to Dubey et al. (2017a) who classified the definitions of SSC management into two broad categories: SSCM as a management philosophy and SSCM as a set of management processes.

\subsubsection{Humanitarian supply chain (HSC)}

Van Wassenhove (2006) defines a disaster as a "disruption that physically affects a system as a whole and threatens its priorities and goals", and the HSC should be designed to support the distribution of emergency goods to alleviate the suffering of people and communities affected by disasters whether they are natural or man-made. Though the specific characteristics of the HSC would depend on the type, nature, magnitude and geographical area of the disaster (Jabbour et al. 2017), HSC can be defined in terms of the logistics activities and coordination involved in managing and coordinating humanitarian aids. From this perspective, Thomas (2003) defined Humanitarian Logistics as "a set of activities that include: preparedness, planning, procurement, storage, transportation, either of relief goods or information, from the point of origin to the point of consumption with the purpose of relieving the suffering of vulnerable people".

By extension and drawing from Christopher's (1992) definition of a supply chain, we can define an HSC as the network of organizations that are involved in the design, management and coordination of the different processes and activities that include preparedness, planning, procurement, storage, transportation and distribution of emergency goods and services from the point of origin to the point of consumption, with the purpose of alleviating the suffering of people and communities affected by disasters whether they are natural or man-made.

Considering the above definitions, we can now discuss the concept of SHSC. Cao et al. (2018) observed that, contrary to what can be said of commercial supply chains, sustainability in the disaster context, being in its early stage, is considered by just a few researchers. In a recent literature review, Dubey and Gunasekaran (2016) also observed that there are relatively few contributions which focus on SHSCs. Therefore, the SHSC concept is still far from attaining maturity. One of the recent attempts comes from Klumpp et al. (2015) who proposed a definition for sustainable humanitarian operations built on a combination of HOs' objectives, logistics definition (from the CSCMP) and the Brundtland sustainable development definition: It states that "Sustainable humanitarian logistics has the objective to assure every human being - especially in situations of disasters and emergencies-a standard of living adequate for the health and well-being of himself and of his family, including food, clothing, housing and medical care and necessary social services by planning, implementing, and controlling the efficient, effective forward and reverse flow and storage of goods, services and related information throughout the whole SC in a manner that meets the needs of the present without compromising the ability of future generations to meet their own needs"

Though this definition includes a large (but fuzzy) view of stakeholders' expectations on sustainability, it contains the key words (more especially, planning) that are used in our research. However, we can improve it by incorporating the key elements of the definitions of sustainability, SSC and HSC that we have discussed in this Sect. 2.1. Hence, we define an SHSC as the network of organizations that are involved in the design, management and coordination of the different processes and activities that include preparedness, planning, procurement, storage, transportation and distribution of emergency goods and services from the point of origin to the point of consumption, with the purpose of alleviating the suffering of people and communities affected by disasters, while transparently and accountably inte- 
grating goals from the economic, social and environmental dimensions of sustainability that are derived from the requirements of the various stakeholders.

\subsection{Sustainability performance measurement}

Performance Measurement (PM) is a way to quantify and control the outcomes obtained on any organization's process. It can be used on the one hand to compare goals, standards, past results or organizations, and on the other hand to anticipate the impact of decisions on planning processes. Neely et al. (1995) defined performance measure as a metric used to quantify the efficiency and/or effectiveness of an action, where effectiveness expresses the extent to which goals are accomplished and efficiency is the measure of how well the expended resources are utilised. This definition is too cost-based to be sufficient in the context of the multidimensional environment of today's supply chains. So, businesses and researchers have developed not only more quantitative but also qualitative measures.

In the SSC literature, many authors have used the TBL performance approach as a basis to define the sustainability of a supply chain (Beske and Seuring 2014; Elkington 1998). Carter and Easton (2011) noted that, given the far-reaching consequences of their activities, supply chain decision makers are in a position to impact performance as regards to the economic, social and environmental dimensions of sustainability. Also, given the definition of sustainability that we presented in Sect. 2.1.1, these are the sustainability performance dimensions that we will use in our model.

\subsection{Master Planning}

Planning is generally done at three levels according to the time horizon: the strategic level for long-term planning, the tactical level for medium-term planning and the operational level for short-term planning (Chopra and Meindl 2004). While strategic supply chain planning concerns capacity investments and facility locations (Kauder and Meyr 2009), tactical supply chain planning addresses allocation rules for resources as well as usage rules that define production, distribution lead times, lot sizing and inventory policies (D'Amours et al. 2008). It also deals with demand forecasting, production planning, supply planning, replenishment planning and transport planning. In other words, tactical planning, aims to define the forecast demand and to find the most suitable way of fulfilling it through an effective management of the assessment, procurement, warehousing and transport processes across an organization's supply network and over a medium-term planning horizon.

This paper focuses on tactical planning. Master Planning, which corresponds to the tactical level planning, allows a link to be made between the strategic decisions and the operational process, and to coordinate the different processes of procurement, warehousing and transport to ensure the fulfilment of needs (Demand Planning). Therefore, this decision level is a lever to improve the performance of the SHSC, as it defines the gross operations that will take place according to the assessed needs. It enables the optimization of HSC flows, and therefore, of operational performance.

\section{Literature review}

In the literature, disaster operations management has often been divided by researchers into four different chronological phases: mitigation, preparedness, response and recovery. The mitigation and preparedness phases constitute pre-disaster phases and aim at lowering the 
probabilities of a disaster occurring or minimizing its possible effects, while the response and recovery phases are post-disaster phases, with the response phase seeking to minimize the disaster's effects and the recovery phase supporting the community in its effort to return to a normal state (Anaya-Arenas et al. 2014). Though we are going to refer to these four phases, this review of the literature will focus more on the preparedness phase which is directly concerned with the tactical planning activity. In line with the title and structure of this paper, we will present the literature review under two sub-sections: (1) Performance measurement and SHSC, and (2) Master Planning and SHSC.

\subsection{Performance measurement and sustainable humanitarian supply chain}

Though HSC represents a young field of research compared to the commercial supply chain, in recent times, more and more researchers have studied issues that are related to the four phases of disaster operations management. However, given that sustainability is a very new stream of research in the HSC management, there are very few publications that are substantially and relevantly focused on performance measures as they apply to SHSCs. Therefore, we will widen the boundary of our review to include publications that deal with performance measurement in HSCs and GSCs, but with respect to the three dimensions of sustainability.

Questioning how supply chain performance can be measured in a humanitarian context where operations simultaneously have multiple goals, Haavisto and Goentzal (2015) observed that the holistic perspective is not much considered in performance measurement of HSCs. Of the thirteen HSC performance measures that they identified in the literature, only two-efficiency and sustainability, can be said to be directly linked to sustainability. D'Haene et al. (2015) tested performance measures from the literature against the current practices of three major humanitarian organizations and their results showed that performance measurement is only partially developed in the three organizations. In effect, none of the three dimensions of sustainability was explicitly mentioned.

In the HSC literature, even though multi-objective problems have been addressed (Gralla et al. 2014), many of the articles study and discuss only one dimension of sustainability. Apart from the economic dimension, which has always been the only natural and historical business performance measure of the traditional supply chain, the environmental dimension is studied more than the social dimension but from the GSC perspective (Green et al. 2012; Jaggernath and Khan 2015; Hervani et al. 2005). Having said this, we note that some publications on GSC (Cosimato and Troisi 2015) mention the social dimension though without much emphasis. Even in the OR literature, most models that suggest key sustainability performance measures quite often refer to the environmental dimension but overlook the social aspects (Carter and Easton 2011). We also note that it is difficult to measure the social dimension due to its qualitative nature as well as the lack of consensus on its definition (Maas and Liket 2011). It follows that the social dimension needs to be further explored (Dubey et al. 2017b).

Some researchers (for example, Gopalakrishnan et al. 2012; Paulraj et al. 2017) have studied the three dimensions of sustainability, but not in the HSC sector. Gopalakrishnan et al. (2012) examined the drivers of sustainability, using a case study of British Aerospace (Bae) Systems; and Paulraj et al. (2017) tested the three dimensions in 259 German firms. Given the large number of studies in the commercial SSC sector, a well-structured benchmarking framework can be developed and used to transfer knowledge to the SHSC sector despite the differences highlighted by Dubey et al. (2017b).

Nevertheless, Kunz and Gold (2017) worked on the design of the recovery phase of an SHSC and in line with the findings of Haavisto and Kovács (2014), they concluded that HSCs consider sustainability only from a double-bottom-line perspective by focusing on economic 


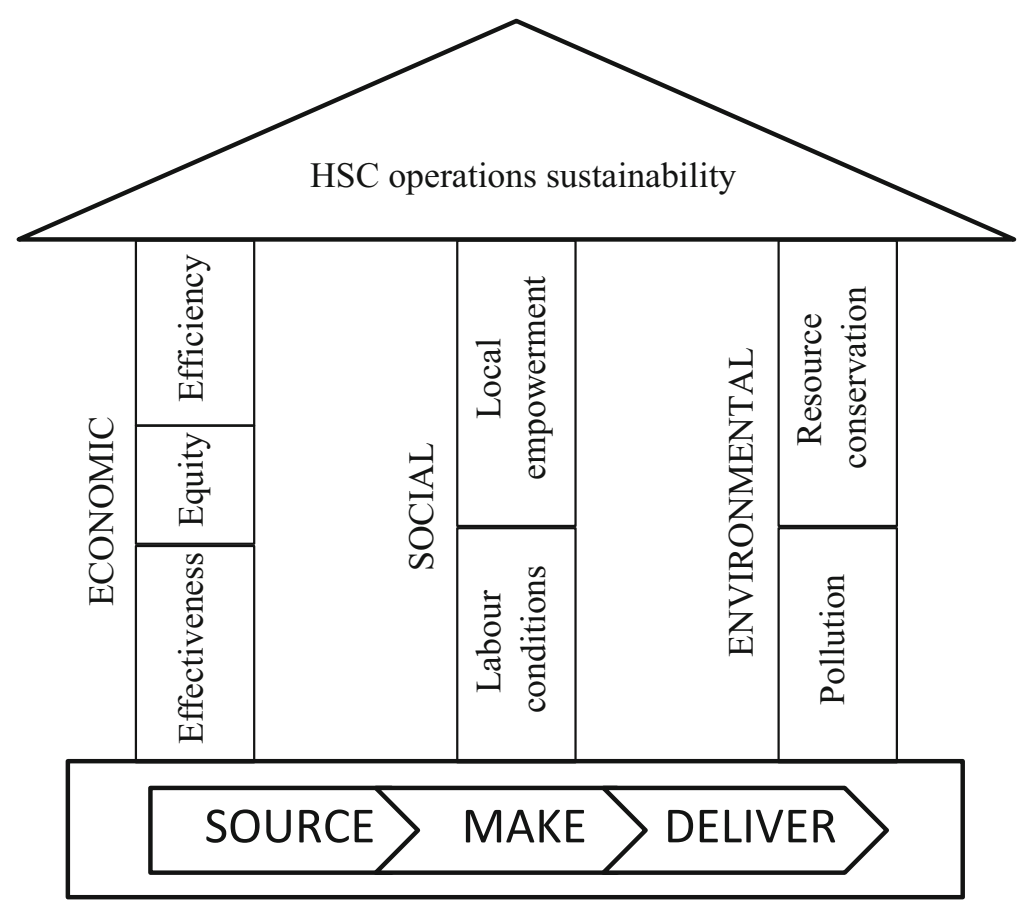

Fig. 2 House of sustainable HSC operations

and social sustainability, and neglecting the environmental dimension. In any case, though some HOs have (to some extent) started taking sustainability objectives into consideration in their strategic plans, they still do not have an integrated TBL approach, which descends to the tactical and operational decision levels. Again, Baumann (2011) proposed an evaluation model to characterize the global performance of an enterprise based on PM aggregation, which is built on the TBL model, but the focus was only on the strategic level of decisionmaking and not on the tactical and operational levels.

The above literature review clearly justifies the aim of this paper to incorporate all the three dimensions of sustainability into a model that will be used for the tactical planning of SHSCs. In a recent research work, Laguna Salvadó et al. (2017) developed a conceptual performance framework for the sustainability of HSC operations based on the TBL model. This model has been called the "House of Sustainable HSC operations" (see Fig. 2). Based on a literature review and field research, it is an attempt to design a framework that includes the economic, social and environmental dimensions of sustainability, and that can be used for studying the performance of SHSCs. It proposes a set of performance measures classified on the TBL performance dimensions that should be considered for SHSC decisionmaking. It covers the HSC main processes (source, make and deliver). This framework is however generic and does not consider the various decision levels (strategic, tactical and operational). Consequently, it does not allow a concrete quantification for the different planning processes.

To summarize, there is no standard definition of sustainability performance measurement despite its importance for HSC decision-making. Numerous objectives can be found in the literature to assess the environmental or social impact of HSCs, but only few authors address all three dimensions. The "House of Sustainable HSC operations" presents a framework to target relevant objectives for each dimension in the context of HSCs, but fails to provide a concrete system for measuring the performance of the different planning processes.

Most of the academic contributions treat sustainability either from a theoretical point of view (Hausladen and Haas 2013) or with a focus on reporting and accountability (Carter and 
Rogers 2008). Motivated by the highly diffuse concept, Haavisto and Kovács (2014) studied how several HOs address expectations related to sustainability in the HSC. Their research results revealed that little attention has been paid to environmentally friendly products, services or operations. They emphasized the fact that some research is needed to find paths or methods to fill the gap between humanitarian needs (response) and sustainability objectives. Even though some organizations eventually consider sustainability objectives, this is developed from a program (long term) perspective, and almost ignored from an operational (shortor medium-term) supply chain perspective.

This paper aims not only to fill this gap, but also to propose some metrics associated with the three dimensions of sustainability that will be integrated into the proposed Master Planning DSS.

\subsection{Master Planning and sustainable humanitarian supply chain}

Although planning DSSs are widely used in commercial SCs, they are not very common in HSCs. To investigate the reasons for this gap, we start by looking at the manner in which HSC planning horizons are broken down, at least in the literature. Blecken (2010) suggested an HSC standard referent model that includes processes and decision levels. In this model, the standard referent decision levels are the same as those in commercial SCs: strategic, tactical and operational, also referred to as long-, mid- and short-term horizon levels (Stadtler 2005). At the strategic level, many HOs have incorporated high-level strategic goals such as the support of local economic growth. This is reflected in Activity Reports from organizations such as the IFRC or OCHA (UN OCHA 2014; Vinck 2013). However, based on field research, Laguna Salvadó et al. (2017) observed that the sustainability approach does not descend to the tactical and operational levels.

In the literature, there is quite a good number of strategic and operational level research works. Contributions on strategic planning focus on inventory planning and coordination, which is achieved through decisions that are made ex-ante on warehouse location and sizing (Balcik and Beamon 2008; Davis et al. 2013; Mete and Zabinsky 2010; Yang et al. 2016), while operational level research works focus on transport planning, especially the last mile distribution problems (Balcik et al. 2008; Özdamar et al. 2004). Vanajakumari et al. (2016) adopted an integrated logistic approach that covers warehouse location, inventory assignment and transportation optimization, but their model still aims essentially at last minute distribution problems. Barbarosoğlu and Arda (2004) developed a generic modelling framework for planning transportation of vital first-aid commodities and emergency personnel to disaster-affected areas. Richardson et al. (2016) proposed ten factors that should be considered in prepositioning locations in humanitarian operations. Though these factors include environmental and social elements, they are focused on inventory prepositioning location decisions rather than on tactical planning. Vega-Mejía et al. (2017) have published one of the most recent and complete literature reviews on the consideration of TBL objectives for sustainability, but once again, it focuses on the optimization of vehicle routing and loading operations, which falls within the scope of operational planning rather than tactical planning.

The tactical level decision-making process aims to find the most suitable way of fulfilling demand forecasts (assessment) through an effective management of the procurement, warehousing and transport processes across an organization's supply network and over a medium-term planning horizon. The research stream on SHSCs still lacks theories (Kunz and Gold 2017) that would enable to develop effective tactical planning systems. Even in commercial SCs, where the research field on SSCs has been growing in recent years, Taticchi 
et al. (2015) came up with the conclusion that there is still need to develop new generation DSSs that incorporate TBL approaches for managing SSCs.

In practice, HSC tactical planning and post-disaster decisions are mainly based on the experience of decision makers (Noham and Tzur 2018) and human behaviour impacts humanitarian problem formulation and solution (Gralla et al. 2016). The tactical decision level has relatively been overlooked in the HSC literature, probably because of the segmented nature of the management of disaster responses within HOs. HSCs have a limited ability to anticipate demand, due to the uncertainty of the occurrence of humanitarian crises. Moreover, HSC managers conceive each disaster response as a single SC solution instead of building a tactical planning system that aggregates the HO's network, in parallel with other on-going operations. Another possible reason is that HOs have very little funds devoted to planning, prevention and preparedness activities (Jahre and Heigh 2008; Tatham and Pettit 2010). Nevertheless, one can find in the literature a few contributions on tactical planning that address the three dimensions of sustainability. However, almost all of them are still limited in their scope not only in terms of the HSC processes that they cover, but also as regards the disaster operations management phases that are concerned. For example, Oloruntoba (2010) studied the key success factors in an emergency relief chain, but his contribution focused more on the response phase and was based on document analysis rather than on the development of a DSS. Rottkemper et al. (2011) developed a planning model for inventory relocation, but their OR model focuses also on the response phase, is only cost-based and does not include the other two TBL sustainability dimensions.

In the commercial SC, before optimization and simulation OR tools entered the “enterprise-planning arena", Master Planning was often done by MRP II systems, or by simple calculations using spreadsheets without considering capacity limitations (Rudberg and Thulin 2009). OR-related DSSs that conduct Master Planning use mathematical programming to maximize performance objectives while including constraints (e.g. capacity) as an integrated part of the planning process. To be able to optimize the Master Planning problem, procurement, inventory and distribution must be monitored. Inputs are forecast demand data and network constraints formulated as a model that defines capacity and dependencies between different processes. According to Fleischmann et al. (2005), cited in Stadtler and Kilger (2005), the three major difficulties in using optimization methods and approaches to define a plan are:

- There are often several metrics, leading to conflicting objectives and ambiguous preferences between alternatives. This is the main concern when introducing a sustainability performance system that considers the three TBL conflicting dimensions.

- A huge number of alternatives are a predominant feature in SC planning. In the case of continuous decision variables (e.g. order sizes), the set of alternatives is infinite.

- When there is uncertainty, the demand forecast may be fuzzy. Moreover, nearly always, reality deviates from the plan, especially in the context of HSC.

Nonetheless, according to Altay and Green (2005) and Galindo and Batta (2013), OR methods have a "tremendous potential" in the disaster response domain. Since 2005, there has been a noticeable increase in the publications that address HSC decision support system problems with OR methods (Charles and Lauras 2011). OR is a well-established discipline regarding allocation of scarce resources, because it offers the tools to support HSC operational decision-making (Pedraza-Martinez et al. 2013). By adapting OR best practices that have been validated in commercial SCs, relevant solutions can be proposed to the complex problems faced by HOs (Charles and Lauras 2011). The methodology used in this paper will be presented and discussed in the next section. 


\section{Research methodology}

The first phase of the work presented in this paper consisted in studying the case of the IFRC's Regional Logistic Unit (RLU) of the American \& Caribbean zone (A\&C) in order to identify weaknesses of the current activity model as regards business processes, decision-making and information systems.

In effect, after conducting preliminary interviews with the Regional Logistics Development Coordinator (RLDC) of the IFRC A\&C RLU, we designed guidelines, observations and mapping supports for semi-structured interviews and focus groups, in line with previous field research that had been carried out by the Disaster Resilience Lab. The fieldwork was conducted during a 10-day mission at the IFRC A\&C RLU Panama site (office and warehouse). We interviewed all members of the RLU structure: head, service officer, procurement officers, logistic officers and warehouse manager and officers as well as the Panama Disaster Response Unit (PADRU) coordinator.

The interviews and observations enabled us to identify the current cartography of the business processes and activities, future evolutions, and practitioners' needs. The analysis of the field work revealed the challenge that is addressed in this paper. Given that the field research was not sufficient to validate our hypothesis on the challenges of the SHSC, we confronted the conclusions of the IFRC field analysis with the academic literature on HSCs and other available secondary information on HOs (reports and websites).

To develop the SHSC planning approach presented in this paper, we used mainly commercial SC and HSC best practices and trends based on the state of the art. The HSC planning model has been built based on the field research observations. Regular exchanges with the IFRC enabled us to validate and improve the assumptions of the model and the case study. Whenever the information from the field was not sufficient, it was completed with information from the literature as related to the HSC.

Due to the multi-objective nature of sustainability performance measurement in a sustainable Master Planning System, decision makers must deal with the conflicting objectives between the economic, social and environmental dimensions of sustainability. We note that in theory all three dimensions need to be considered, but in practice they have different relative importance in any given real-life planning situation. Though many OR modelling approaches can be found in the literature to solve such multi-objective decision problems (MODP), it is still difficulty to find a solution that adequately takes into consideration the decision maker's preferences and priorities.

In line with the sustainability performance multi-dimensional problem, the lexicographic ordering method (LOM) enables the decision maker to first rank the objective functions according to some subjective degree of priority, before using a multi-stage optimization algorithm to find a solution (Branke 2008; Rentmeesters et al. 1996; Sherali 1982). It enables to avoid specifying an abstract weight between objectives if the decision maker only has to rank the objectives by priority.

However, combining different methods could help to improve the preferred plan. In the literature, there exists an extension of the LOM (Rastegar and Khorram 2015; Wray et al. 2015), which introduces a slack component. With ex-ante (a priori) LOM, it is very likely that the process stops before less important objective functions are taken into consideration. With the slack or constraint relaxation, the interactive LOM (ILOM) increases the number of possible feasible solutions at each stage. The decision maker can interact with the algorithm by defining a small deviation from the optimal value of a primary variable such as to improve the secondary value functions. Interactive methods are interesting because they allow the 


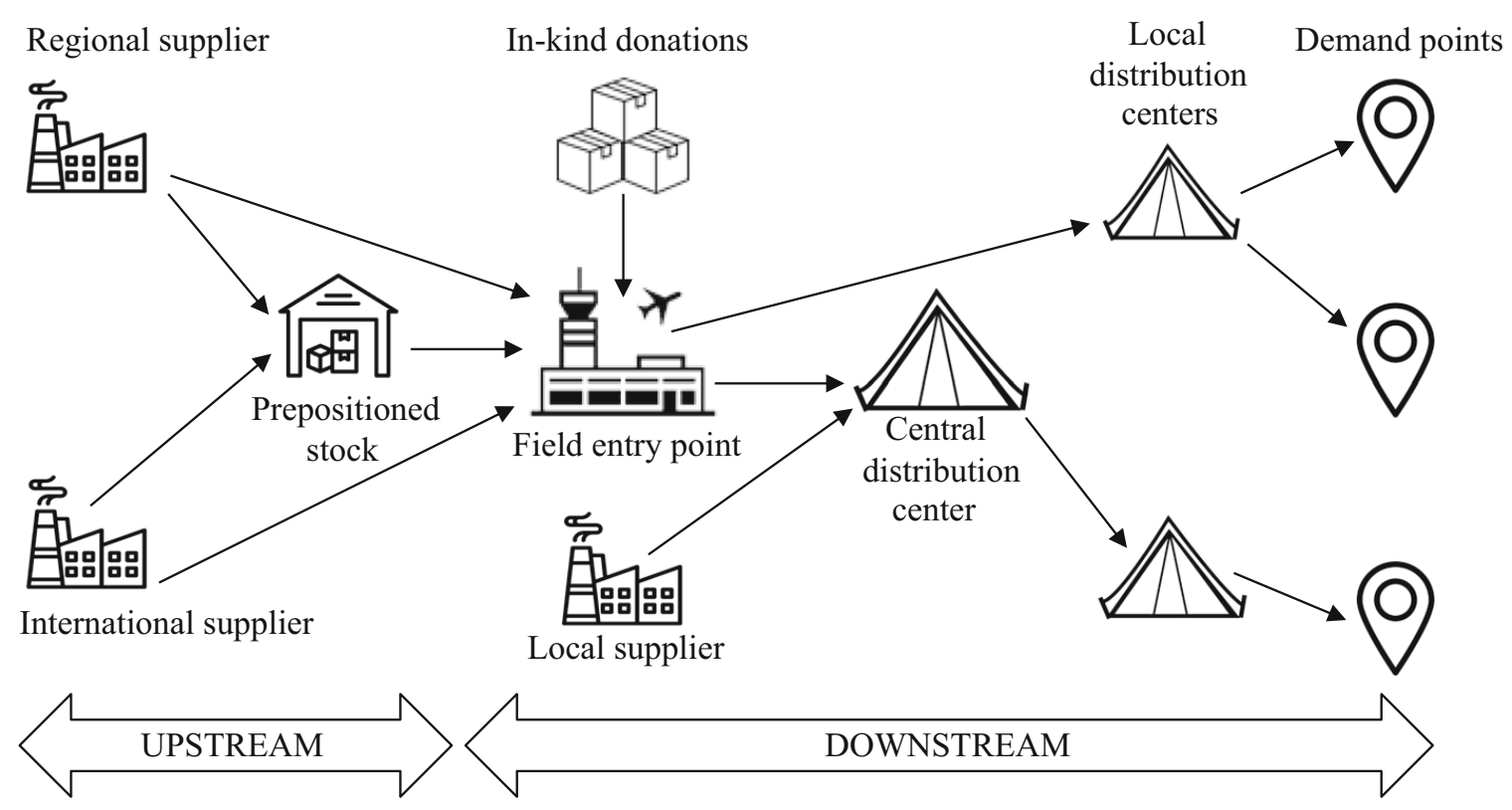

Fig. 3 The HSC network

readjustment of the ex-ante inputs or the introduction of additional information depending on the behaviour of the model. Thus, the decision maker can direct the solution process toward preferred solutions.

\section{Proposal of an SHSC Master Planning DSS}

In this section, we present the decision-making problem and the SHSC Master Planning DSS that includes three components:

- a set of HSC sustainability performance measures

- an ILOM algorithm to solve the multi-objective problem

- an SHSC Master Planning Model.

For a better understanding of our proposal, we will first present the HSC network before presenting the above components.

\subsection{The HSC network}

The main service that the HSC provides is the management of the procurement, warehousing and distribution processes of emergency products from suppliers to beneficiaries. Except for kitting, no transformation is made on the emergency products. A typical HSC network connects suppliers, warehouses and demand points through transportation flows (see Fig. 3). The upstream HSC deals with the aggregate demands of all future and ongoing humanitarian crises.

When a sudden onset disaster occurs, the distribution strategy is to push products from prepositioned contingency stocks into the country as soon as the humanitarian needs are estimated. If the response capacity of contingency stock is exhausted, a pull model is then set up to source additional items from suppliers. This hybrid model enables to rapidly satisfy the first needs and gives decision makers some buffer time to plan the upcoming procurement activities. 
The SHSC Master Planning DSS must define the material flow from suppliers to the demand points. Therefore, the problem boils down to answering the following questions on a medium-term horizon:

- What items should be delivered (product references)?

- How much of each item should be delivered (quantity)?

- When should the items be delivered (schedule)?

- Who should provide the items (suppliers/warehouses)?

- Where should the items be delivered (warehouses/demand points)?

- How should the items de moved (transportation mode)?

In other words, the question is how to choose between all potential material flow combinations (within a given network and for each planning horizon) those that fulfil the demand with the best acceptable performance on the three dimensions of sustainability.

\subsection{Determination of a set of HSC sustainability performance measures}

To solve the sustainable Master Planning problem, we need to quantify the impact of material flows on sustainability performance. A discussion of the three dimensions of sustainability (economic, social and environmental) will enable to determine a set of SHSC performance measures as well as associated metrics for the quantification.

\subsubsection{The economic dimension}

For the economic dimension, the "House of Sustainable HSC operations" shows three main measures: effectiveness, efficiency and equity. Master Planning decisions have an impact on all three measures.

Effectiveness is the capability of achieving the organization's target (Abidi et al. 2014). By allocating (or not) the necessary items and organizing transportation to a demand point, the Master Planning decisions have a direct impact on demand fulfilment. If the demand exceeds the available resources, the decision maker's objective would be to minimize suffering. A typical metric for measuring effectiveness is fulfilment rate, which is determined by dividing the correctly serviced demand by the total demand. The information to quantify this measure ex-post can easily be gathered if the demand is well defined and the distribution operations tracked. At the planning phase, it is also relatively simple to determine theoretical effectiveness values, though these may differ from actual values due to uncertainty and risks in the HSC.

Efficiency measures how well the resources are utilized (Abidi et al. 2014). In an HSC, this measure corresponds to the minimization of costs. Cost is a common performance measure in supply chain management and has already been used as an objective function in many academic humanitarian distribution models (Balcik and Beamon 2008). Master Planning decisions have a direct impact on the three main cost components in a supply chain: cost of acquisition, cost of distribution and inventory holding cost. Real costs are difficult to measure. However, the aim of planning is to compare potential alternatives. Though the values may not be accurate, finding comparable value magnitudes on the acquisition and distribution (transportation) costs may be sufficient to distinguish between the options. Inventory holding costs are typically computed as a percentage of the stock level value.

Equity is a component of the impartiality fundamental principle of the IFRC and it is one of the values expected by stakeholders (donors and beneficiaries). There is no standard quantification method for equity and it has been overlooked in extant literature (Balcik et al. 2010). 
Tzur (2016) measured the equity of HSCs using the Gini Index, a non-linear measurement of inequality. Other authors have used the deprivation cost approach (Holguín-Veras et al. 2013) or the amount of suffering of the victims or the disparity in demand fulfilment (Huang et al. 2012). In the Master Planning problem, we consider equity as a constraint, which ensures that the resources are shared proportionally and equitably between the affected populations.

\subsubsection{The social dimension}

The social impact is difficult to measure due to lack of standards (Maas and Liket 2011). To quantify the impact of procurement and distribution activities on the social dimension the "House of Sustainable HSC operations" indicates two main measures: labour conditions and local empowerment.

Labour conditions is a broad concept that may include work quality and safety. It can be measured using the Health-Safety-Environmental (HSE) quality assessment model. However, Master Planning decisions do not have a direct impact on the employees' labour conditions. This criterion could be considered at the strategic decision level. For example, in the suppliers selection process, it can be controlled by considering only suppliers who ensure acceptable labour conditions for their employees. At the operational decision level, it can be obtained by measuring the impact of scheduling decisions on the labour conditions of employees.

Regarding local empowerment, Master Planning decisions can impact it by investing humanitarian funds in the local market. This has been a controversial issue due to the potential unbalance of the local economy and generation of inequality (FAO 2006). Nonetheless, today, developing the local economy is a strategic goal for many organizations, notably HOs. It is a way of strengthening the resilience of the communities to recover and mitigate future disasters. We note that this is mentioned in IFRC's 2020 strategic plan (IFRC 2010). The WFP has also developed cash-based transfers to beneficiaries to incentivize the local market (WFP 2017). Thus, the decision of sourcing locally or internationally can contribute to the development of resilience (the choice of local suppliers). This is measured in the Master Planning system as the fraction of investment/operating expenses made at the local level over the total amount of investment/operating expenses.

\subsubsection{The environmental dimension}

In the "House of Sustainable HSC operations", the environmental dimension is composed of two main measures: pollution reduction and resource conservation. The material flow processes have a direct impact on both measures.

The aim of pollution reduction is to decrease the emission of harmful or poisonous substances such as $\mathrm{CO}_{2}$ into the atmosphere. Depending on the choice of transportation modes and distances between suppliers and beneficiaries, Master Planning decisions have a direct impact on pollution reduction. In this regard, we retain the most common metric-the $\mathrm{CO}_{2}$ footprint - that enables to compare transportation alternatives.

Resource conservation is about the reasonable use and protection of valuable resources such as trees, minerals, wildlife and water. With respect to the choice of packaging materials, handling processes or recovery policies, the impact on this parameter may be placed at the strategic level. It is difficult to assess the impact of tactical decisions on resource conservation. Thus, this measure is not considered for the sustainability performance of the Master Planning. 
Table 1 Sustainability performance measures and metrics

\begin{tabular}{lll}
\hline TBL dimensions & Performance measures & Performance metrics \\
\hline Economic & Effectiveness & Fulfilment rate of needs \\
& Efficiency & Operations cost \\
Social & Local empowerment & Local sourcing rate \\
Environmental & Pollution reduction & Carbon footprint \\
\hline
\end{tabular}

\subsubsection{The retained set of SHSC performance measures}

The discussion of the three dimensions of sustainability has enabled us to determine and retain four sustainability performance measures: effectiveness, efficiency, local empowerment and pollution reduction. Table 1 summarizes the set of metrics used to quantify these four measures: fulfilment rate for effectiveness, operations cost for efficiency, local sourcing rate for local empowerment and $\mathrm{CO}_{2}$ footprint for pollution reduction. Though all four of them have to be considered, effectiveness is essential to maintaining HSC activities and the value chain. Therefore, in this paper, it is considered hereafter as a prerequisite in the SHSC. Hence, it has a bigger relative importance than the other three measures and is integrated in the ILOM approach as the 1st lexicographic order (presented in the next section). The other three measures have a conditional lexicographic order depending on situational state variables such as strategic priorities and the gap between available funds and needs.

With the aim to simplify the understanding of the SHSC Master Planning ILOM algorithm and the mathematical model, effectiveness is defined separately from the conditional lexicographic TBL dimensions.

\subsection{Interactive algorithm to solve the multi-objective problem}

To plan the HSC processes from a sustainability perspective, the four metrics that we retained in Sect. 5.2 have to be considered in a multi-objective optimization problem. It is unlikely to find a single solution that simultaneously satisfies each optimal objective. If the decision maker has an active role and can prioritize the performance measures ex-ante, we propose to solve the problem using the interactive variant of the ILOM. Effectiveness is an essential and prerequisite measure. The other three measures (efficiency, local empowerment and pollution reduction) may be prioritized depending on state variables: the decision level, HSC network perimeters (single or inter-organizational; upstream or downstream) or situation (disaster response, replenishment).

The proposed algorithm is illustrated as a flow chart in Fig. 4. The pool on the left represents the decision maker's tasks, while the pool on the right represents the DSS activities. The algorithm solves the SHSC Master Planning problem considering the four performance measures. The execution starts when the decision maker wants to define a Master Plan for HSC operations. But before then, (s)he has to define the HSC network model to identify potential suppliers, warehouses, forecasted needs and potential transportation flows.

The algorithm is formulated as follows:

(a) The first task of the decision maker is to rank the sustainability performance dimensions (economic, social and environmental) according to their relative importance or LO. This input gives the optimization order to the DSS $\left(\mathrm{LO}^{1}, \mathrm{LO}^{2}, \mathrm{LO}^{3}\right) . \mathrm{LO}^{0}$ is the effectiveness, which is not prioritized but rather considered as a prerequisite. 


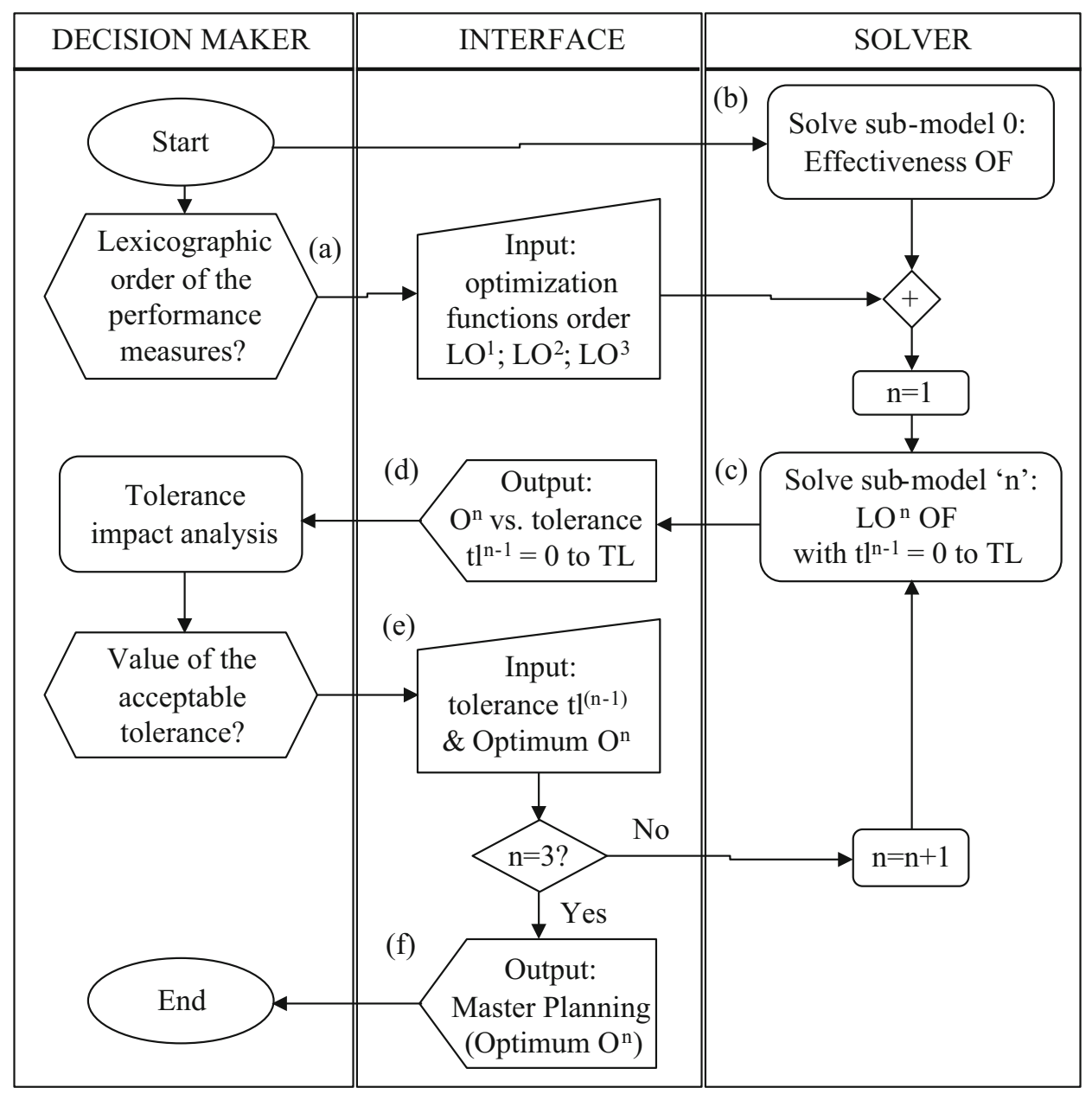

Legend:

$\bigcirc$ Start/end process $\square$ DM's input $\square$ Task $\square$ Display $\square$ Decision

Fig. 4 ILOM algorithm for SHSC Master Planning DSS

(b) For the DSS, the first activity is to solve the optimization problem with the effectiveness objective function (OF). The output of this activity (solving sub-model 0 ) is the effectiveness optimal value $\left(\mathrm{O}^{0}\right)$ that the model can attain with the network and forecasted demand.

\section{- Sub-model 0}

Optimize: Effectiveness Objective Function

Subject to: HSC Master Planning model

(c) The loop (n from 1 to 3 ) starts with one iteration per criterion. Following the LO approach, the sub-model ' $n$ ' is constrained by the previous (n-1) optimal value found, but with a tolerance defined by the decision maker. To define this tolerance, the DSS computes $\mathrm{O}^{\mathrm{n}}$ with a variation on the $\mathrm{O}^{\mathrm{n}-1}$ tolerance level $(\mathrm{tl})$. For the first iteration, $\mathrm{LO}^{\mathrm{n}-1}$ is the effectiveness, so the DSS optimizes the $\mathrm{LO}^{1}$ objective function (either economic, social or environmental) with a variation on the effectiveness constraint tolerance.

\section{- Sub-model 1}

From $t l=0$ to $t l=T L ;($ tolerance variation)

Optimize: LO $O^{l}$ Objective Function

Subject to: HSC Master Planning model+Effectiveness constraint [tl] 
(d) The result is displayed to the decision maker, who decides which is the most "acceptable" trade-off: deteriorating the effectiveness optimal value or improving the $\mathrm{O}^{1}$ optimal value. Then, s(he) fixes the pair: $\mathrm{O}^{1}$ optimal value and tolerance level $\mathrm{tl}^{0}$. These values serve as input for the DSS.

(e) The second loop $(\mathrm{n}=2)$ will repeat the process with $\mathrm{LO}^{1}$ and $\mathrm{LO}^{2}$ in order to define $\mathrm{O}^{2}$ optimal value and tolerance level $\mathrm{tl}^{1}$, while the third loop $(\mathrm{n}=3)$ repeats the process with $\mathrm{LO}^{2}$ and $\mathrm{LO}^{3}$ in order to define $\mathrm{O}^{3}$ optimal value and tolerance level $\mathrm{tl}^{2}$,

\section{- Sub-model 2}

From $t l=0$ to $t l=T L ;($ tolerance variation)

Optimize: LO $O^{2}$ Objective Function

Subject to: HSC Master Planning model + Effectiveness constraint $\left[t l^{0}\right]+L^{1}$ constraint [tl]

- Sub-model 3

From $t l=0$ to $t l=T L$;

Optimize: LO $O^{3}$ Objective Function

Subject to: HSC Master Planning model + Effectiveness constraint $\left[\mathrm{tl}^{0}\right]+\mathrm{LO}^{1}$ constraint $\left[t l^{1}\right]+L O^{2}$ constraint [tl]

(f) At the end of the third loop, the output is the most acceptable Master plan, based on the LO optimization and the decision maker's expertise.

\subsection{The SHSC Master Planning model}

The SHSC Master Planning model is a variant of the network flow problem (Bradley et al. 1977). The main differences that we address are based on the following:

- the HSC network provides more than one product,

- the optimization objectives are multiple since sustainability is multidimensional

- the problem is solved considering several time periods (over the planning horizon).

The supply network is composed of three elements: suppliers, warehouses and customers. The model is sufficiently abstract to represent a large variety of HSC designs and perimeters. Suppliers are the source of relief products. Depending on the perimeter, they can be private sector providers or other HOs that are specialized in the distribution of relief products. Warehouse refers to the intermediate locations where relief products are stored, but can also represent permanent locations with contingency stocks or warehouses deployed when a disaster occurs. Customer refers to the demand points of relief products, but can also be a field entry point (hub or warehouse), a distribution point or the warehouse of a third-party organization. The sources, destinations, and intermediate points are the nodes of the network, while the transportation links connecting the nodes (or flows) are the arcs. As in a classical problem, the suppliers' capacity and the total number of products required by the customers are assumed to be known. The products can be sent directly from sources to destinations, or may be routed or sourced through intermediate points (warehouses).

The Master Planning is calculated for a given number of periods on a pre-defined planning horizon. Whereas in the industrial sector the tactical level typically considers 6-12 months, in the HSC this period may be shorter due to uncertainties, and depending on the HSC perimeters considered. The last-mile distribution activity may be characterised by a shorter planning horizon and granularity than the upstream HSC (permanent network of prepositioned stocks). 
The mathematical model (objects and parameters, objective functions and constraints) presented hereunder is developed based on both the field research presented in the methodology section and information gathered from the literature. All the network elements are supposed to be known ex-ante by the decision maker.

\subsubsection{Model objects and parameters}

In this section, we define all the components of the SHSC Master Planning model: the indices and the objects composed of parameters and variables.

\section{Model indices}

Indices

$\mathrm{t} \quad \mathrm{t} €[1 . . \mathrm{nbT}]$ time periods (nbT is the total number of periods)

f Flow record index

s Product-supplier record index defined by (sid, sprod)

w Product-warehouse record index defined by (wid, wprod)

c Product-customer (demand point) record index defined by (cid, cprod)

\section{Distribution flow object}

The distribution flow object gathers the data related to the physical connections between the network nodes. Each record is a physical connection between nodes, unique for each product.

Input parameters

Fori(f) Origin

fdes(f) Destination

fpro(f) Product reference

ftlt(f) Lead time (or flow $\Delta \mathrm{t}$ )

fitc(f) Product acquisition cost

fcost(f) Cost (acquisition and transport) per unit

fenv(f) $\quad \mathrm{CO}_{2}$ emission par unit

fsoc(f) Defines nearness: 1 if local, 0 otherwise

fope $(t, f) \quad 1$ if the flow is operational at period $t, 0$ otherwise

$f \exp (t, f)$ Expected receipt of products, defined before $t_{0}$

\section{Variables}

Fin(t,f) Quantity of products received at destination (fdes) at period $t$

Fout $(t, f)$ Quantity of products shipped from origin (fori) at period $t$

\section{Customer-product (demand point) object}

Each record relates to one product and demand point all over the planning horizon.

Input parameters

cid(c) Customer identification

cpro(c) Product reference

cunc(c) Product standard cost

cqua(t,c) Units of products needed at period $t$ 
ctqua(c) Estimated value of the total amount of products needed by the customer during the planning horizon

cpri(t,c) Priority of the needs/penalty par unit

Variables

Cin $(\mathrm{t}, \mathrm{c}) \quad$ Units of products received by the customer at period $\mathrm{t}$

Csto(t,c) Units of stockout products at period $t$

Cove $(t, c)$ Units of overstock products at period $t$

Ctpen(c) Total stockout penalty value over the planning horizon

\section{Supplier-product object}

Each record relates to one product and sourcing point all over the planning horizon.

Input parameters

Sid(s) Supplier identification

Spro(s) Product reference

ssca $(\mathrm{t}, \mathrm{s})$ Supplier shipment capacity for product $\mathrm{p}$ at period $\mathrm{t}$

Variable

Sout $(\mathrm{t}, \mathrm{s})$ Products shipped at period $\mathrm{t}$

\section{Warehouse-product object}

Each record relates to one product inventory and location all over the planning horizon.

Input parameters

wid(w) Warehouse identification

wpro(w) Product reference

wini (w) Initial inventory level

wreq(w) Expected contingency stock level

wtreq(w) Expected contingency stock value

wunc(c) Product standard cost

Variables

Winv(t,w) Warehouse inventory level at period $\mathrm{t}$

Wsto(t,w) Warehouse contingency stockout

Wove $(\mathrm{t}, \mathrm{w})$ Warehouse contingency overstock

Wtavg(w) Warehouse average inventory level

Wtpen $(\mathrm{w})$ Warehouse total penalty over the planning horizon

\section{Other parameters}

Each record relates to one constraint regarding the TBL performance measures.

Input parameters

Effopt Optimal effectiveness constraint

efftol Effectiveness constraint tolerance

envopt Optimal pollution reduction constraint

envtol Pollution reduction constraint tolerance

socopt Optimal local empowerment constraint

soctol Local empowerment constraint tolerance

ecoopt Optimal efficiency constraint

ecotol Efficiency constraint tolerance 


\subsubsection{Objective functions}

In this sub-section, we will present four objective functions, each representing one of the performance measures. The order of the general constraints depends on the optimization sequencing.

\section{Objective function for effectiveness}

The objective function for effectiveness aims to find a feasible distribution plan that maximizes the fulfilment of demand on time. It is computed as the maximum value that can be achieved if everything is delivered on time minus the penalty for delays. The maximum value refers to the value of the total demand for a given period multiplied by its priority factor plus the contingency stock value of one period. The customer penalty is evaluated as the total stockout quantity par period multiplied by the priority level of each demand and the product's standard unit value. The warehouse penalty is evaluated as the total stockout quantity per period multiplied by the product's standard unit value. Both penalties are divided by the total number of periods (nbT)

$$
\operatorname{Max} \sum_{c} \operatorname{ctqua}(c)-\sum_{c} \operatorname{Ctpen}(c) / n b T+\sum_{w} w \operatorname{treq}(w)-\sum_{w} W \operatorname{tpen}(w) / n b T
$$

where

$$
\begin{gathered}
\operatorname{ctqua}(c)=\sum_{t} \text { cqua }(c, t) \times \operatorname{cpri}(c) \times \operatorname{cunc}(c) \\
\text { Ctpen }(c)=\sum_{t} \operatorname{Csto}(c, t) \times \operatorname{cpri}(c) \times \operatorname{cunc}(c) \\
\text { wtreq }(w)=\operatorname{wreq}(w) \times \text { wunc }(w) \\
\text { Wtpen }(w)=\sum_{t} \text { Wsto }(w, t) \times \text { wunc }(w)
\end{gathered}
$$

\section{Objective function for efficiency (economic dimension)}

The objective function for efficiency aims to minimize procurement and distribution costs while satisfying the needs. In our model, the fixed cost of procurement is not taken into consideration since the cost function is proportional to the product flow (quantity delivered).

$$
\operatorname{Min} \sum_{f} \sum_{t} F i n(f, t) \times f \cos t(f)
$$

\section{Objective function for pollution reduction (environmental dimension)}

The objective function for pollution reduction aims to minimize carbon emission in the procurement and distribution activities. To compute the unitary emission of a shipped product, the Greenhouse Gas protocol is the most common model (Absi et al. 2013). The total amount is calculated with a linear function that depends on both the distance travelled and the carbon emission of the vehicle used $\left(\mathrm{g} \mathrm{CO}_{2} / \mathrm{km}\right)$. Based on this model, the carbon emission metric is proportional to the number of units of products allocated to each flow in the network, depending on the transportation flow. 


$$
\operatorname{Min} \sum_{f} \sum_{t} \operatorname{Fin}(f, t) \times f e n v(f)
$$

\section{Objective function for local empowerment (social dimension)}

The objective function for local empowerment aims to maximize local investments on procurement activities. In other words, this objective function maximizes purchases from local suppliers. Local suppliers are determined by the decision maker and include those located not only in the same region, but also in neighbouring countries.

$$
\operatorname{Max} \sum_{f \mid f \text { soc }=\text { local }} \sum_{t} \text { Fin }(f, t) \times f i t c(f)
$$

\subsubsection{Constraints}

The objective functions defined in Sect. 5.4.2 are subject to two categories of constraints: general and sustainability performance.

\section{General constraints}

\section{Flow-balance}

The flow-balance constraints apply the conservation-of-flow law which states that for all inflow records (Fin), when the time is equal to or less than the flow lead time, the inflow can only be the delivery quantities scheduled before $t_{0}(f \exp )$.

$$
\operatorname{Fin}(f, t)=f \exp (f, t), \quad \forall \mathrm{f} \forall \mathrm{t} / \mathrm{t} \leq \mathrm{ftlt}(\mathrm{f})
$$

Another way of expressing them is that the inflow record (Fin) is equivalent to the outflow (Fout) from a node before the flow $\Delta \mathrm{t}$.

$$
\operatorname{Fin}(f, t)=\operatorname{Fout}(f, t-f t l t(f)), \quad \forall f \forall \mathrm{t} / \mathrm{t}>\mathrm{ftlt}(\mathrm{f})
$$

\section{Supplier-balance}

The supplier-balance constraint stipulates that for each supplier-product record, the quantity of products dispatched at period t must be equal to the sum of all the inbound flows at period $\mathrm{t}$ for which the point of origin and product are the same as for the supplier-product couple.

$$
\operatorname{Sout}(s, t)=\sum_{f \mid \operatorname{Fori}(f)=\operatorname{sid}(s) \& \operatorname{fpro}(f)=\operatorname{spro}(s)} \operatorname{Fout}(f, t), \quad \forall \mathrm{s} \forall \mathrm{t}
$$

Maximum capacity of suppliers

The quantity of products dispatched must not exceed the maximum capacity of the suppliers per period.

$$
\operatorname{Sout}(s, t) \leq \operatorname{ssca}(s, t), \quad \forall \mathrm{s} \forall \mathrm{t}
$$




\section{Warehouse inventory-balance}

For each warehouse-product couple, the inventory level (Winv) at the previous period $t-1$ plus the quantity of products received during period $t$ is equal to the inventory level at period $t$ plus the quantity of products dispatched during period $t$. For the first planning period $(t=1)$, the warehouse inventory level at period $\mathrm{t}-1$ is the parameter wini (initial inventory level).

$$
\begin{aligned}
& \operatorname{wini}(w)+\sum_{f \mid f \operatorname{des}(f)=\operatorname{wid}(w) \& \operatorname{fpro}(f)=\operatorname{wpro}(w)} \operatorname{Fin}(f, 1) \\
& =\operatorname{Winv}(w, 1)+\sum_{f \mid \operatorname{fori}(f)=\operatorname{wid}(w) \& \operatorname{fpro}(f)=\operatorname{wpro}(w)} \operatorname{Fout}(f, 1) \quad \forall \mathrm{w}, \mathrm{t}=1 \\
& \operatorname{winv}(w, t-1)+\sum_{f \mid f \operatorname{des}(f)=\operatorname{Fid}(w) \& f \operatorname{pro}(f)=\operatorname{wpro}(w)} \operatorname{Fout}(f, \mathrm{t}) \\
& =\operatorname{Winv}(w, \mathrm{t})+\sum_{f \mid \operatorname{fori}(f)=w i d(w) \& f \operatorname{pro}(f)=\operatorname{wpro}(w)} \quad \forall \mathrm{w}, \mathrm{t}>1
\end{aligned}
$$

Satisfaction of the warehouse contingency stock level

The stockout quantity (Wsto) refers to the difference between the desired contingency stock and the actual inventory level. It becomes an overstock (Wove) if the requested quantity is less than the inventory level.

$$
\operatorname{Winv}(w, t)-\operatorname{wreq}(w)=\text { Wove }(w, t)-\operatorname{Wsto}(w, t), \quad \forall \mathrm{w}, \forall \mathrm{t}
$$

We note that at the end of the planning horizon, the forecasted demand may tend to be underestimated (the demand estimation veracity and the forecasted quantities decrease with the time periods) due to the unexpected consequences and behaviour of humanitarian crisis. Hence, the model forces the network to finish the planned period with the required contingency stock level. This prevents the economic objective function from depleting the contingency stocks.

$$
\text { Winv }(\mathrm{w}, \mathrm{nbT})=\mathrm{wreq}(\mathrm{w}), \quad \forall \mathrm{w}
$$

\section{Customer (or demand point) balance}

For each demand point-product couple, the quantity of products received per period is equal to the sum of all the inbound flows (Fin).

$$
\operatorname{Cin}(c, t)=\sum_{f \mid f \operatorname{des}(f)=\operatorname{cid}(c) \& \operatorname{fpro}(f)=\operatorname{cpro}(c)} \operatorname{Fin}(f, t) \quad \forall \mathrm{c}, \forall \mathrm{t}
$$

\section{Demand fulfilment}

The quantity of products that a demand point receives at period t must be equal to the demand (cqua). It may be lower in case of stockout or higher due to overstock.

$$
\begin{gathered}
\text { Cin }(c, 1)+\text { Csto }(c, 1)=\text { cqua }(c, 1)+\text { Cove }(c, 1), \quad \forall \mathrm{c}, \mathrm{t}=1 \\
\text { Cin }(c, t)+\text { Csto }(c, t)=\text { cqua }(c, t)+\text { Cove }(c, t)+\text { Csto }(c, t-1)-\operatorname{Cove}(c, t-1), \quad \forall \mathrm{c}, \mathrm{t}>1
\end{gathered}
$$

However, given that the objective is to respond to all the demands and that the network can achieve this a priori, the model forces the fulfilment of all the demands.

$$
\sum_{t} \operatorname{creq}(\mathrm{c}, \mathrm{t})=\sum_{t} \operatorname{Cin}(\mathrm{c}, \mathrm{t}), \quad \forall \mathrm{c}, \forall \mathrm{t}
$$




\section{Equity constraint}

The equity constraint forces the distribution of products to be proportional to demand, with the same ratio for all the priority customers (level 1) and a tolerance of $10 \%$.

$$
\sum_{t} \operatorname{Csto}(c, t) / \sum_{t} \text { Cqua }(c, t)<\left(\sum_{c} \sum_{t} C s t o(c, t) / \sum_{c} \sum_{t} \text { Cqua }(c, t)\right) \times 1.1, \quad \forall \mathrm{c} / \mathrm{cpen}(\mathrm{c})=\text { Level } 1
$$

\section{Sustainability performance constraints}

\section{Effectiveness constraint}

The effectiveness constraint is the maximum value obtained by the objective function for effectiveness (Effopt) minus a given tolerance level (tl\%).

$$
\begin{aligned}
\text { Effopt }[1-(1-\text { efftol })] \leq & \sum_{c} \text { ctqua }(c)-\sum_{c} \operatorname{Ctpen}(c) / n b T \\
& +\sum_{w} w \operatorname{treq}(w)-\sum_{w} W \operatorname{treq}(w) / n b T
\end{aligned}
$$

Efficiency (economic) constraint

The economic constraint is the minimum value obtained by the objective function for economic (Ecoopt) plus a given tolerance $(\%)$.

$$
\text { Ecoopt } \times(1+\text { ecotol }) \geq \sum F i n(f) \times f \operatorname{cost}(f)
$$

Pollution reduction (environmental) constraint

The environmental constraint is the minimum value obtained by the objective function for environmental (Envopt) plus a given tolerance (\%).

$$
\text { Envopt } \times(1+\text { envtol }) \geq \sum F i n(f) \times f e n v(f)
$$

Local empowerment (social) constraint

The social constraint is the maximum value obtained by the objective function for social (Socopt) minus a given tolerance (\%).

$$
\text { Socopt }-(\text { Socopt } \times \text { soctol }) \leq \sum_{f \mid f \text { soc }=\text { local }} \sum_{t} \text { Fin }(f, t) \times \text { fitc }(f)
$$

\section{Illustrative case, results and discussions}

To illustrate the SHSC Master Planning model, we present a case based on the IFRC A\&C HSC. We will first describe the case before presenting a numerical application of the SHSC Master Planning DSS. Then, we will present the results and discussion.

\subsection{The IFRC American \& Caribbean upstream HSC}

The IFRC HSC is composed of a set of Regional Logistic Units (RLU) that are strategically located to respond to humanitarian needs, one of which is in Panamá (with the mission of covering the American and Caribbean region). The IFRC's strategy is to develop sub-regional 
warehouses called Logistic Units (LU) whose mission is to develop local procurement, warehousing and distribution capabilities. This strategy is developed with the involvement of IFRC National Societies, which are expected to own and manage the LUs while benefiting from the centralized expertise of the Panama RLU. Today, even though some difficulties (funding, turnover, etc.) are encountered in sustaining these sub-regional structures, some of the LUs still exist (for example, Guatemala, Nicaragua, Honduras, Ecuador). These permanent warehouses constitute the core of the "upstream" IFRC HSC (see Fig. 3).

We developed this Master Planning case based on the field study at the Panama RLU as well as on interviews with the Regional Logistic Development Officer. We also built it by imagining what the future IFRC upstream HSC would look like.

\subsubsection{American \& Caribbean IFRC sub-regional upstream network}

The scope of the Master Planning decisions englobes the emergency product flows from suppliers to the field entry points. The network is composed of 7 LUs and the Panama RLU. All warehouses are located close to the respective capitals and in proximity of logistic infrastructures such as seaports and/or airports. The contingency stock level of each LU is defined by the IFRC strategy. The Panama RLU has a contingency stock level that corresponds to the needs of 5000 families. LUs have smaller quantities, which can support between 2000 and 5000 families depending on the country.

Though the IFRC catalogue has many thousands of references, only a few products that correspond to basic needs (for hygiene, shelter and kitchen for example) are kept in the contingency stock at the LUs and RLUs depending on the specificities (climate and culture for example) of the affected region. For the illustrative purpose of our model, we have selected only two products, one that can be sourced locally (blankets) and one that is difficult to find (tents) even at the national level in most of the countries of the region.

Despite long lead times, most of the suppliers are based in Asian countries due to their competitive prices. At the country level, there are few local suppliers that impact positively on local empowerment and are competitively responsive. The sub-regionalization strategy helps to promote and enhance local capacity, with the aim to develop local sourcing. For our case study, we shortlisted 12 potential suppliers for blankets and 6 for tents. Blankets are considered to be sourced only locally due to the important demand for IFRC standard products.

\subsubsection{Evaluation of needs}

The main service offered by the IFRC upstream HSC is the management of procurement, warehousing and distribution processes of emergency products to feed entry points (warehouses, airports, seaports, etc.). It does not cover last-mile delivery. The demands can be classified into different categories depending on the origin or the priority level. Regarding the origin of the orders, the IFRC supplies third-party humanitarian actors such as NGOs (for example, OXFAM) or Governments. However, the main "customers" are the National Societies and Emergency Response Units (ERUs) of the IFRC. Regarding the priority level, the demands can also be classified into different categories depending on the level of the disaster and the phase of the disaster cycle: Response (push products), Recovery (pull products), Mitigation/Preparation (build or replenish stocks). The upstream network responds to simultaneous needs. Therefore, the resulting demand corresponds to the aggregation of all the orders from the different origins and priority. 
In this paper, we consider that the evaluation of the demand is not within the scope of the Master Planning process. Based on available data, we consider that demand forecast can be done for a planning horizon of 3 months and a time period of 1 week. The demand is based on the socio-economic situation and the political instability of most of the countries in the area as well as on natural phenomena (such as El Niño) that make the population especially vulnerable.

The LO of the performance objectives has to be established by the decision maker. Funding is always a problem since the characteristically recurrent disasters affecting this area do not receive the attention of the media. The strategy of the IFRC is to give more priority to the development of local markets than to environmental considerations. Therefore, it is assumed in this paper that the decision maker prioritizes the three sustainability dimensions in the following order: economic, social and environmental.

\subsection{Numerical application}

Based on the case studied, we built a database for the network flow. This database is composed of four sub-databases that can be seen in "Appendix 1". They are: (1) information concerning the suppliers, (2) warehouse inventory input data of LUs and the RLU, (3) demand input data, and 4) input data of flows. The initial inventory corresponds to the target contingency stock level. The demand input data correspond to the estimated needs per product and per demand point for the first 7 weeks of the planning horizon. The "cpen" value represents the priority of the order (the higher this parameter, the higher the priority). The flow database is composed of 150 flows from suppliers to LUs and the RLU. To limit the quantity of flows, it is assumed that suppliers do not deliver directly to the field. The parameters used to define each flow are: origin, destination, mode, distance, lead time, product environmental impact, product economic impact, product social impact, and the outstanding orders (expected receipts).

\subsection{Results and discussions}

We will first present an illustration of the decision-making process with one LO. Then, we will present an Experimental Plan that shows the behaviour of the model when all the potential LOs are considered. Finally, the interest of using the interactive tolerance variation will be discussed.

\subsubsection{The Master Planning for the SHSC}

We simulated the decision-making process based on the ILOM proposed in Fig. 4. The lexicographic order is:

- LO ${ }^{0}:$ Effectiveness

- $\mathrm{LO}^{1}$ : Economic

$-\mathrm{LO}^{2}:$ Social

- $\mathrm{LO}^{3}$ : Environmental

The first optimization step aims to maximize the effectiveness of the SHSC $\left(\mathrm{LO}^{0}\right)$. Then, following the algorithm, the economic optimum $\left(\mathrm{LO}^{1}\right)$ is calculated with the effectiveness optimum, with a tolerance variation as a constraint. The interface shows the results of varying the effectiveness tolerance level. In the example, the computation was done using variations that go from 0 to $20 \%$ with an incremental step of $1 \%$ (see Fig. 5).

We observe that demand fulfilment, which is the main performance driver, is not impacted by small tolerance variations. Small tolerances induce delays only on the inventory levels 


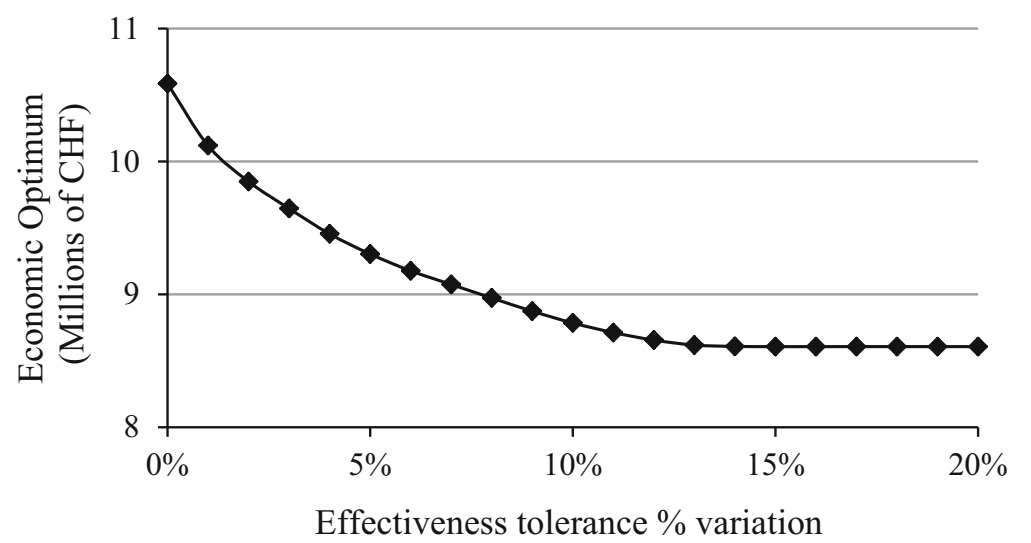

Fig. 5 First iteration output: Economic metrics vs. Effectiveness tolerance variation

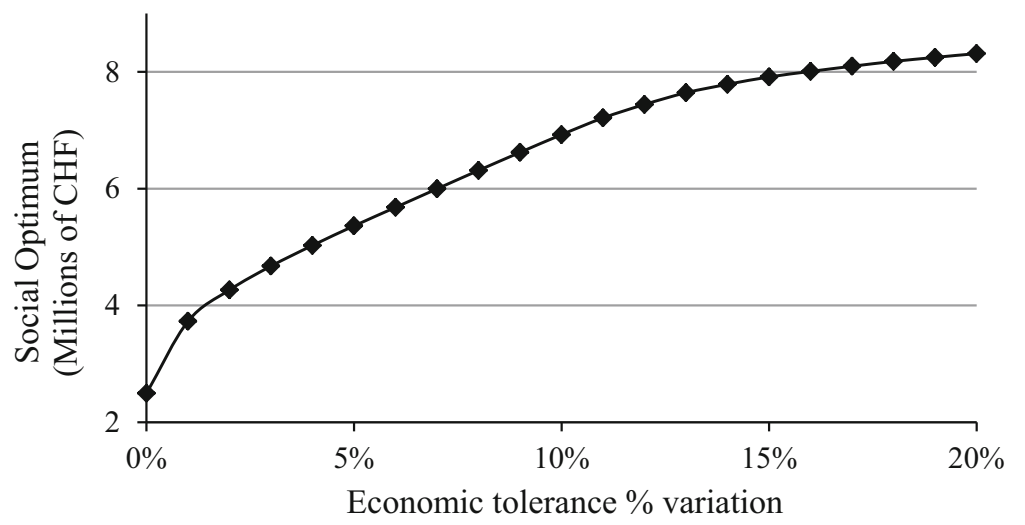

Fig. 6 Second iteration output: Social metrics vs. Economic tolerance variation

in the warehouses. To illustrate the decision-making algorithm, we assume that the decision maker chose to sacrifice $2 \%$.

With $2 \%$ tolerance, the effectiveness constraint is then fixed at 27 million $\mathrm{CHF}$ and the minimum economic optimum at 10 million CHF.

Then, the second iteration loop computes the social optimum $\left(\mathrm{LO}^{2}\right)$ with the fixed effectiveness constraint plus the variation of the economic optimum $\left(\mathrm{LO}^{1}\right)$ as a constraint. The result is shown in Fig. 6.

Considering that a degradation of $2 \%$ of the economic optimum (about 10,000 CHF) allows the social optimum to increase by about 1.2 Million CHF, we assume that the decision maker accepts a $1 \%$ tolerance on the economic optimum. The economic constraint is then fixed at 9.9 million $\mathrm{CHF}$ and the social optimum $\left(\mathrm{LO}^{2}\right)$ at 3.7 million $\mathrm{CHF}$.

The last optimization loop computes the environmental optimum $\left(\mathrm{LO}^{3}\right)$ with the social optimum $\left(\mathrm{LO}^{2}\right)$ tolerance variation as a constraint. It varies from 0 to $20 \%$, with incremental steps of $1 \%$. The interface with the decision maker shows the resulting graph (see Fig. 7).

The output graph resulting from the third iteration leaves a little choice margin for the decision maker. Reducing the social optimum by $1 \%$ (37 thousand CHF) allows an improvement of 17.7 thousand CHF on the carbon footprint, whereas a reduction of $2 \%$ (63 thousand $\mathrm{CHF}$ ) leads to an improvement of 18.5 thousand CHF. The assumption is therefore to accept a tolerance of $1 \%$. The social constraint is then fixed at 3.7 Million CHF and the minimum environmental optimum $\left(\mathrm{LO}^{3}\right)$ at 0.41 Million CHF. The resulting Master Planning performance measures are summarized in Table 2. 


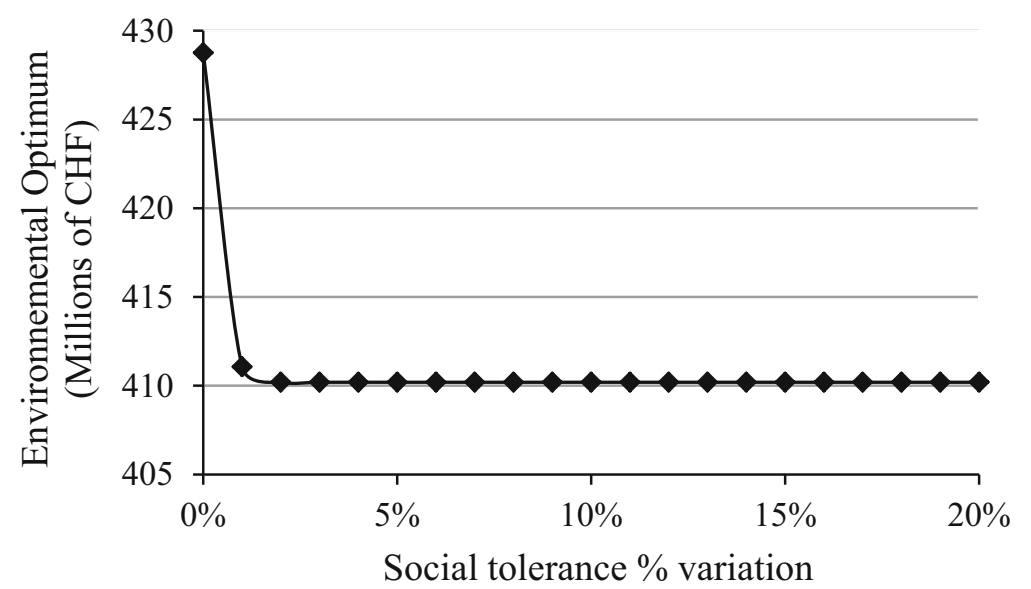

Fig. 7 Third iteration output: Environmental metrics vs. Social tolerance variation

Table 2 Results of the Master Planning performance metrics

\begin{tabular}{lllll}
\hline & Effectiveness & Economic & Social & Environmental \\
\hline Accepted tolerance & $2 \%$ & $1 \%$ & $1 \%$ & - \\
Value & $27,000,000 \mathrm{CHF}$ & $9,900,000 \mathrm{CHF}$ & $3,700,000 \mathrm{CHF}$ & $410,000 \mathrm{CHF}$ \\
\hline
\end{tabular}

In addition to the performance measures, the model outputs are the weekly procurement and distribution flows. Table 3 shows a sample of the Master Planning flows allocation for the SHSC.

The decision maker has also access to the planning of receipts, the eventual stockouts (or overstocks) and the expected inventory levels.

\subsubsection{Experimental plan of lexicographic orders (LOs)}

For a better understanding of the proposed Master Planning DSS for an SHSC and the behaviour of the algorithm, we built an experimental plan with all the possible lexicographic orders. Given that effectiveness is considered as a fixed LO objective and that only the other three objectives (economic, social and environmental) have to be ordered, there are six possible LO combinations of the performance measures. The six combinations can be seen in "Appendix 2".

Figure 8 shows how the optimal values of the three TBL metrics evolve with the tolerance variation of effectiveness. All the objectives $\mathrm{LO}^{1}$ benefit from the relaxation of the $\mathrm{LO}^{0}$ (effectiveness). The improvements on the objectives go up to a decrease of $95 \%$ for the environmental impact and an increase of $20 \%$ for the social impact.

The results of $\mathrm{LO}^{1}, \mathrm{LO}^{2}$ and $\mathrm{LO}^{3}$ depend on the tolerance defined for $\mathrm{LO}^{0}$. Fixing the tolerance at $2 \%$ for $\mathrm{LO}^{0}$ (effectiveness), we observed that $\mathrm{LO}^{1}$ and $\mathrm{LO}^{2}$ tolerances also have an impact on the next optimization sequences.

Table 4 shows the results of the experimental plan of the LO with the case data first set at a tolerance of $2 \%$ for $\mathrm{LO}^{0} ; 0 \%$ for $\mathrm{LO}^{1}$ and $0 \%$ for $\mathrm{LO}^{2}$ (Table 4 ) and then at $2 \%$ for $\mathrm{LO}^{0}$; $1 \%$ for $\mathrm{LO}^{1}$ and $1 \%$ for $\mathrm{LO}^{2}$ (Table 4). The measures are normalized based on the optimal result that can be achieved with the $\mathrm{LO}^{0}$ tolerance fixed at $2 \%$. The results show that both the LO and the tolerance variation have a relevant impact on the measures. It can be observed that with a $0 \%$ tolerance (Table 4 ) the order of $\mathrm{LO}^{2}$ and $\mathrm{LO}^{3}$ has no impact on the measures, 


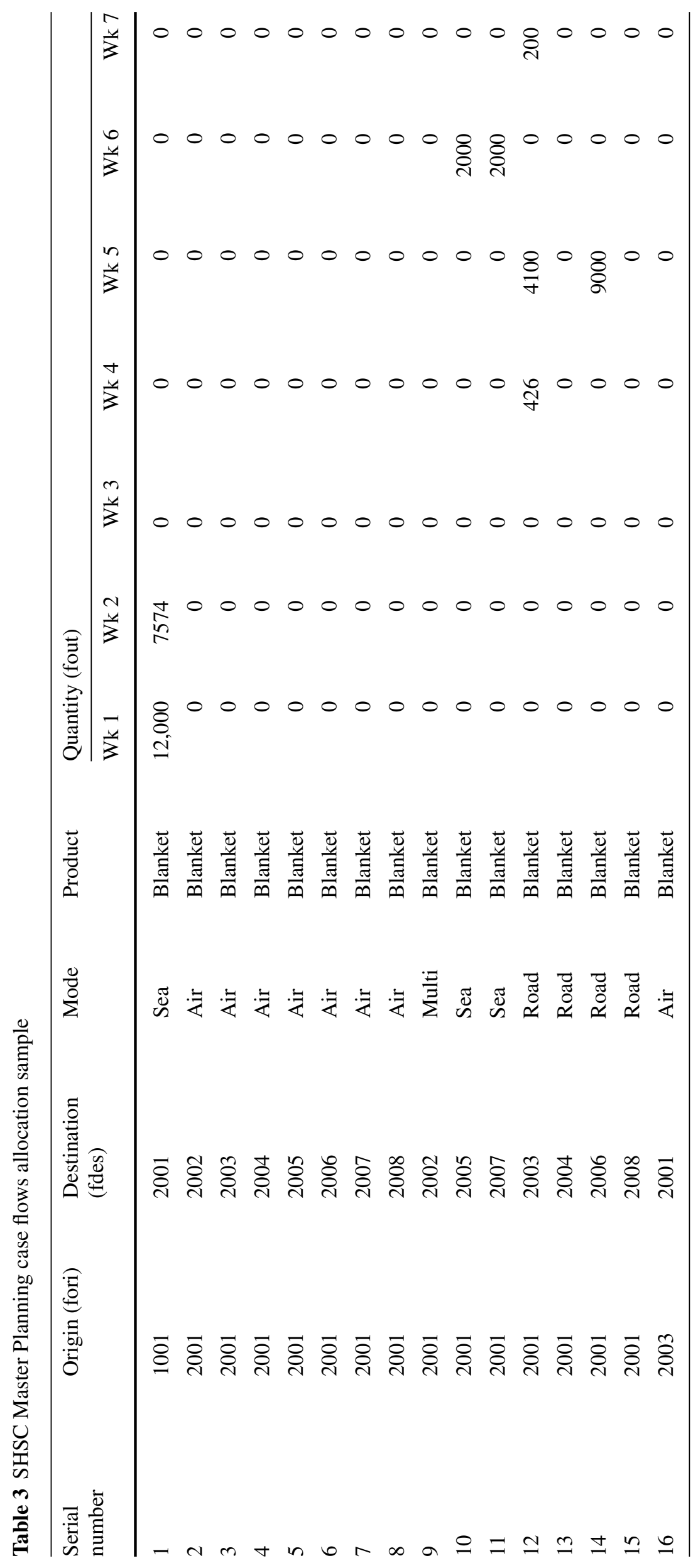




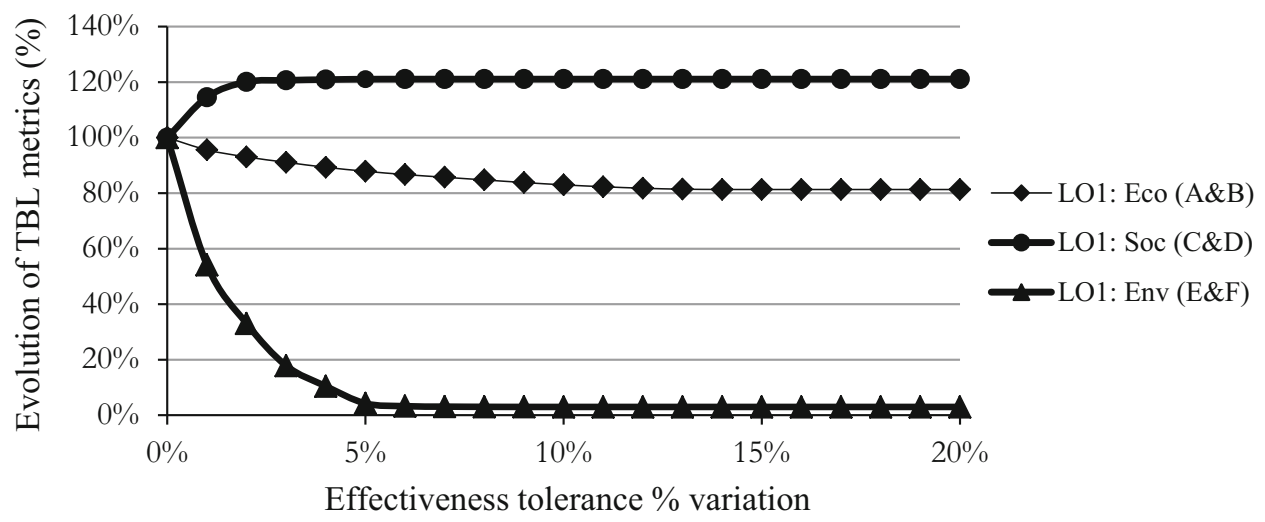

Fig. 8 Variation of the TBL metrics $\left(\mathrm{LO}^{1}\right)$ while varying effectiveness tolerance

Table 4 Experimental plan (for a: tolerance $=0$, and for $\mathrm{b}$ : tolerance $=1 \%$ )

${ }^{\mathrm{F}}$ Effectiveness; ${ }^{\mathrm{C}}$ Economic; ${ }^{\mathrm{S}}$ Social; ${ }^{\mathrm{V}}$ Environmental

\begin{tabular}{lllll}
\hline Tolerance & $\mathrm{LO}^{0}$ & $\mathrm{LO}^{1}$ & $\mathrm{LO}^{2}$ & $\mathrm{LO}^{3}$ \\
& $2 \%$ & $0 \%$ & $0 \%$ & $0 \%$ \\
\hline
\end{tabular}

(a)

\begin{tabular}{lllll} 
Plan A & $98 \% \mathrm{~F}$ & $100 \% \mathrm{C}$ & $30 \% \mathrm{~S}$ & $160 \% \mathrm{~V}$ \\
Plan B & $98 \% \mathrm{~F}$ & $100 \% \mathrm{C}$ & $160 \% \mathrm{~V}$ & $30 \% \mathrm{~S}$ \\
Plan C & $98 \% \mathrm{~F}$ & $100 \% \mathrm{~S}$ & $125 \% \mathrm{C}$ & $324 \% \mathrm{~V}$ \\
Plan D & $98 \% \mathrm{~F}$ & $100 \% \mathrm{~S}$ & $324 \% \mathrm{~V}$ & $125 \% \mathrm{C}$ \\
Plan E & $98 \% \mathrm{~F}$ & $100 \% \mathrm{~V}$ & $110 \% \mathrm{C}$ & $81 \% \mathrm{~S}$ \\
Plan F & $98 \% \mathrm{~F}$ & $100 \% \mathrm{~V}$ & $81 \% \mathrm{~S}$ & $110 \%^{\mathrm{C}}$ \\
\hline Tolerance & $\mathrm{LO}^{0}$ & $\mathrm{LO}^{1}$ & $\mathrm{LO}^{2}$ & $\mathrm{LO}^{3}$ \\
& $2 \%$ & $1 \%$ & $1 \%$ & $1 \%$ \\
\hline
\end{tabular}

(b)

\begin{tabular}{|c|c|c|c|c|}
\hline Plan A & $98 \% \mathrm{~F}$ & $101 \% \mathrm{C}$ & $44 \% \mathrm{~S}$ & $112 \% \mathrm{~V}$ \\
\hline Plan B & $98 \% \mathrm{~F}$ & $101 \% \mathrm{C}$ & $113 \% \mathrm{~V}$ & $44 \% \mathrm{~S}$ \\
\hline Plan C & $98 \% \mathrm{~F}$ & $99 \% \mathrm{~S}$ & $121 \% \mathrm{C}$ & $238 \% \mathrm{~V}$ \\
\hline Plan D & $98 \% \mathrm{~F}$ & $99 \% \mathrm{~S}$ & $241 \% \mathrm{~V}$ & $121 \% \mathrm{C}$ \\
\hline Plan E & $98 \% \mathrm{~F}$ & $101 \% \mathrm{~V}$ & $108 \% \mathrm{C}$ & $73 \% \mathrm{~S}$ \\
\hline Plan F & $98 \% \mathrm{~F}$ & $101 \% \mathrm{~V}$ & $82 \% \mathrm{~S}$ & $110 \% \mathrm{C}$ \\
\hline
\end{tabular}

while with a $1 \%$ tolerance (Table 4 ) there is a significant impact of the order on the measures. It is therefore important to fix the tolerance using an interactive method since it may lead to an important degradation of the measures, which may not be acceptable by the decision maker.

\section{Conclusions}

Given the growing interest in incorporating sustainability performance objectives in the management of humanitarian supply chains (HSCs), both academics and humanitarian organizations (HOs) are in search of effective methods for the implementation of the three sustainability dimensions (economic, social and environmental). This is the object of this 
paper. We will present our conclusions under four sub-sections: final remarks, further research directions, managerial implications, and limitations.

\subsection{Final remarks}

In this paper, we have proposed an approach that can be used for the tactical planning of sustainable operations in humanitarian supply chains (HSC). Based on the one hand, on information gathered from the sustainable HSC and performance measurement literature, and on the other hand, on field research, we presented a Master Planning decision support system (that includes three complementary components) for managing a sustainable humanitarian supply chain (SHSC).

We started by defining a set of performance measures used to quantify the SHSC Master Planning performance. A brief discussion enabled us to retain four parameters (Effectiveness, Efficiency, Local empowerment and Pollution reduction) as the key performance measures for the SHSC Master Planning model. To solve the multi-objective problem, we presented an ILOM approach. This sequential and interactive optimization algorithm enables to take into consideration the expertise of the decision maker (DM) by prioritizing the performance objectives. This allows solving a sequence of single-objective problems while progressively adding the optima of previous solutions as constraints. Finally, we proposed an SHSC Master Planning mathematical model to implement the algorithm.

For the numerical illustration of the proposed DSS, we built a case inspired from the American \& Caribbean IFRC Regional upstream network. The outcome of the case shows how the ILOM approach enables to integrate the DM's expertise and knowledge of the prioritization of planning performance objectives. In this experimental section, we emphasized the interest of using an interactive approach to define tolerances. We note that an interactive approach is mandatory since there is no trivial method for identifying ex-ante the impact of tolerance on performance objectives.

Given that the concept of SHSC has not attained maturity, we also proposed a definition that would on the one hand enable researchers to formulate more relevant and focused research statements and questions, and on the other hand facilitate the implementation of SHSC concepts and tools by practitioners.

\subsection{Further research directions}

Based on the work done and the results of this study, we suggest the following research directions.

- Firstly, applying the proposed model to real-life humanitarian operations would enable to test its operational validity, utility and limitations. Such a project is currently going on with the Asian RLU of IFRC.

- The second research theme would consist in assessing the accuracy of our ILOM outputs with respect to current practices. Our proposal is mathematically and theoretically valid but the relevance of the outputs remains to be studied and confirmed.

- The third would consist in extending the experimental plan to dataset combinations in order to better support decision makers in using the SHSC Master Planning DSS that corresponds to their own business objectives. Though we were able to develop a business case to concretely test our proposal, the parametrization remains complex for users who have to make a lot of intermediate choices in the process. Therefore, it might be valuable to help them by performing a sensitivity analysis of our model and by suggesting sets of parameters, depending on the target objective (especially regarding the tolerance ratios). 
- The fourth would consist in considering much more variability and uncertainty in the proposed SHSC Master Planning DSS. Currently, our proposal is purely deterministic and the hazards are only managed through the rolling horizon of the plan. For further research, it may be interesting to use a stochastic or fuzzy approach.

- The fifth perspective for further research would consist in extending the SHSC Master Planning to a global HSC management model, just as the for-profit business sectors are doing with Advanced Planning Systems.

- Finally, empirical research results have shown that institutional pressures and organizational culture can shape a sustainability performance measurement system (Dubey et al. 2017c). In our view, the cultural factor should include donor behaviour, which has been modelized by Ülkü et al. (2015). Therefore, it would be interesting to investigate how these factors may impact on the implementation of a Master Planning system by humanitarian organizations.

\subsection{Managerial implications}

The integration of economic, social and environmental performance measures into the proposed Master Planning DSS would enable managers to improve the performance of HSC processes in terms of sustainability. Also, given that Master Planning allows not only to make a link between strategic decisions and operational processes, but also to coordinate the different processes of procurement, warehousing and transport to ensure the fulfilment of needs, it is an enabler that can help managers to improve SHSC performance, as it defines the gross operations that will take place according to the assessed demand. It enables the optimization of HSC flows, and therefore, of operational performance. Furthermore, as in commercial SCs, HSC decision makers may also benefit from the mass of information and decision parameters incorporated into the tactical planning DSS by using them to enhance responsiveness at the response phase of the disaster operations management.

However, Master Planning approaches are an attempt to "computerize" planning. Therefore, decision makers have to be aware that they should remain only a decision support system since they constitute a form of relaxation and prevision of real situations. In other words, human knowledge will still be essential to bridging the gap between models and reality. Otherwise, OR solutions in general, and Master Planning DSSs in particular, will hardly ever be adopted, especially in the context of humanitarian operations.

Also, the results of our illustrative numerical example show that managers can use the proposed model to prioritize the three sustainability dimensions and to fix a tolerance that would enable them to obtain an acceptable balance (trade-off) between the three sustainability performance objectives.

Finally, most stakeholders (donors) want to know whether the operations they support have a positive and consequential impact on their communities (Medina-Borja and Triantis 2014). Ülkû et al. (2015) modelled the impact of donor behaviour on humanitarian aid operations and highlighted the importance of educating donors to prepare and assure them in advance that their donations will be effectively and efficiently used for the good cause. We therefore argue that a Master Planning DSS that aims to measure sustainability performance would provide valuable data that can be used to motivate and attract potential donors. This would enable the HO to develop sustainability as a critical success factor that constitutes a competitive advantage. 


\subsection{Limitations}

The illustration that we presented showed that our proposal allows finding sustainable alternatives for supporting humanitarian logistics. However, this illustration also indicated that decision makers have a lot of intermediate choices to make all through the process in order to get a good solution (prioritizing the TBL performance dimensions and fixing the tolerance ratios). All these intermediate decisions can be difficult to make in an emergency context. Moreover, such a Master Planning DSS (as in the case of any planning system) needs a lot of data to run correctly. But in an HSC, this kind of dataset is not easy to put together and could constitute a strong limitation of our proposal. Nevertheless, practitioners already collect such kinds of data (on demand, suppliers, etc.) but maybe not in such an exhaustive manner.

\section{Appendix 1: Network flow database}

\begin{tabular}{|c|c|c|c|c|c|}
\hline Supplier code & Supplier location & Supplier & Item & $\begin{array}{l}\text { Factory price par } \\
\text { unit }(\mathrm{CHF})\end{array}$ & $\begin{array}{l}\text { Supply } \\
\text { capacity/week }\end{array}$ \\
\hline \multicolumn{6}{|c|}{ (a) Supplier data } \\
\hline 1001 & International & Relief supplier A & $\begin{array}{c}\text { Blanket light } \\
\text { thermal }\end{array}$ & 6 & 12,000 \\
\hline 1002 & International & Relief supplier B & $\begin{array}{c}\text { Blanket light } \\
\text { thermal }\end{array}$ & 5 & 13,750 \\
\hline 1003 & International & Relief supplier C & $\begin{array}{c}\text { Blanket light } \\
\text { thermal }\end{array}$ & 7 & 9900 \\
\hline 1006 & International & Relief supplier D & Family tent & 150 & 2000 \\
\hline 1009 & International & Relief supplier E & Family tent & 160 & 2000 \\
\hline 1009 & International & Relief supplier E & $\begin{array}{c}\text { Blanket light } \\
\text { thermal }\end{array}$ & 6 & 1200 \\
\hline 1010 & International & Relief supplier F & Family tent & 170 & 3000 \\
\hline 1011 & International & Relief supplier G & $\begin{array}{c}\text { Blanket light } \\
\text { thermal }\end{array}$ & 6 & 5000 \\
\hline 1012 & Regional & Panama supplier & $\begin{array}{c}\text { Blanket light } \\
\text { thermal }\end{array}$ & 8 & 6000 \\
\hline 1012 & Regional & Panama supplier & Family tent & 300 & 1000 \\
\hline 1013 & Local & $\begin{array}{r}\text { Nicaragua } \\
\text { supplier }\end{array}$ & Family tent & 250 & 500 \\
\hline 1014 & Local & $\begin{array}{r}\text { Colombia } \\
\text { supplier }\end{array}$ & Family tent & 250 & 500 \\
\hline 1014 & Local & $\begin{array}{r}\text { Colombia } \\
\text { supplier }\end{array}$ & $\begin{array}{c}\text { Blanket light } \\
\text { thermal }\end{array}$ & 7 & 5000 \\
\hline 1015 & Local & $\begin{array}{l}\text { Honduras } \\
\text { supplier }\end{array}$ & $\begin{array}{c}\text { Blanket light } \\
\text { thermal }\end{array}$ & 7 & 5000 \\
\hline
\end{tabular}




\begin{tabular}{|c|c|c|c|c|c|}
\hline Supplier code & Supplier location & Supplier & Item & $\begin{array}{l}\text { Factory price par } \\
\text { unit }(\mathrm{CHF})\end{array}$ & $\begin{array}{l}\text { Supply } \\
\text { capacity/week }\end{array}$ \\
\hline 1016 & Local & $\begin{array}{c}\text { Guatemala } \\
\text { supplier }\end{array}$ & $\begin{array}{l}\text { Blanket light } \\
\text { thermal }\end{array}$ & 7 & 5000 \\
\hline 1017 & Local & $\begin{array}{l}\text { Dom. Rep. } \\
\text { supplier }\end{array}$ & $\begin{array}{l}\text { Blanket light } \\
\text { thermal }\end{array}$ & 7 & 5000 \\
\hline 1018 & Local & $\begin{array}{l}\text { Costa Rica } \\
\text { supplier }\end{array}$ & $\begin{array}{l}\text { Blanket light } \\
\text { thermal }\end{array}$ & 7 & 5000 \\
\hline 1013 & Local & $\begin{array}{r}\text { Nicaragua } \\
\text { supplier }\end{array}$ & $\begin{array}{l}\text { Blanket light } \\
\text { thermal }\end{array}$ & 7 & 5000 \\
\hline
\end{tabular}

\begin{tabular}{|c|c|c|c|c|}
\hline Serial number & Warehouse code & National society & $\begin{array}{l}\text { Blanket contingency } \\
\text { stock }\end{array}$ & $\begin{array}{l}\text { Family tent } \\
\text { contingency stock }\end{array}$ \\
\hline
\end{tabular}

(b) Inventory input data of the $R L U$ and $L U s$

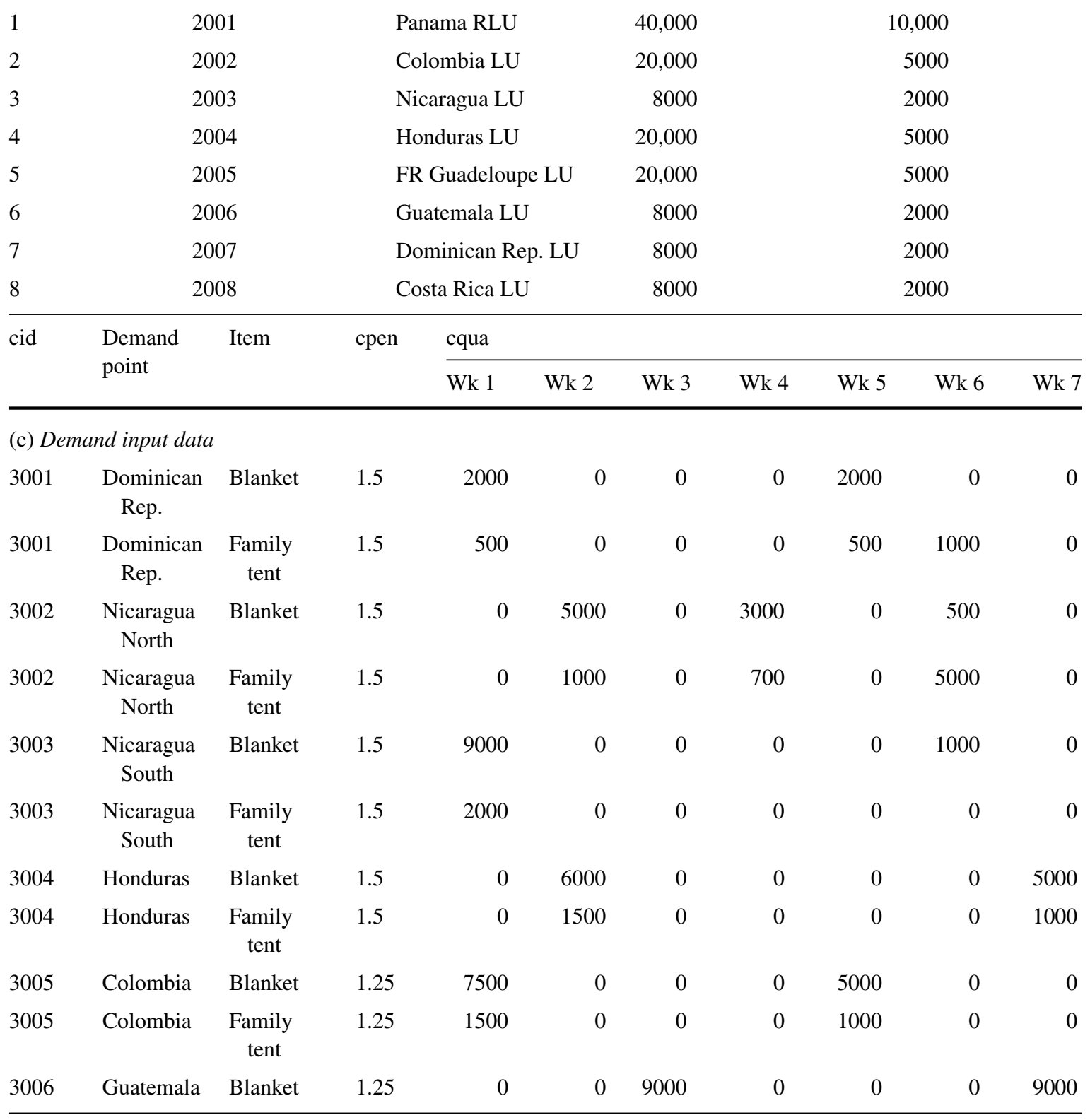




\begin{tabular}{|c|c|c|c|c|c|c|c|c|c|c|}
\hline \multirow[t]{2}{*}{ cid } & \multirow{2}{*}{$\begin{array}{l}\text { Demand } \\
\text { point }\end{array}$} & \multirow[t]{2}{*}{ Item } & \multirow[t]{2}{*}{ cpen } & \multicolumn{7}{|l|}{ cqua } \\
\hline & & & & Wk 1 & Wk 2 & Wk 3 & Wk 4 & Wk 5 & Wk 6 & Wk 7 \\
\hline 3006 & Guatemala & $\begin{array}{c}\text { Family } \\
\text { tent }\end{array}$ & 1.25 & 0 & 0 & 3000 & 0 & 0 & 0 & 3000 \\
\hline 3007 & Haiti & Blanket & 1.5 & 20,000 & 10,000 & 0 & 0 & 0 & 0 & 0 \\
\hline 3007 & Haiti & $\begin{array}{c}\text { Family } \\
\text { tent }\end{array}$ & 1.5 & 5000 & 5000 & 0 & 0 & 0 & 0 & 0 \\
\hline 3008 & $\begin{array}{l}\text { Haiti } \\
\text { NGO }\end{array}$ & Blanket & 1.1 & 0 & 2000 & 0 & 0 & 0 & 2500 & 0 \\
\hline 3008 & $\begin{array}{l}\text { Haiti } \\
\text { NGO }\end{array}$ & $\begin{array}{c}\text { Family } \\
\text { tent }\end{array}$ & 1.1 & 0 & 500 & 0 & 0 & 0 & 600 & 0 \\
\hline \multirow[t]{2}{*}{$\begin{array}{l}\text { Serial } \\
\text { number }\end{array}$} & Origin & Destination & Mode & $\begin{array}{l}\text { Lead } \\
\text { time }\end{array}$ & Product & $\mathrm{CO}^{2} /$ unit & Cost/unit & Social & fexp & \\
\hline & fori & fdes & & ftlt & & fenv & fcost & fsoc & Wk 1 & Wk 2 \\
\hline \multicolumn{11}{|c|}{ (d) Input data of flows } \\
\hline 1 & 1001 & 2001 & Sea & 2 & Blanket & 0.0182 & 5.011 & 0 & 0 & 0 \\
\hline 2 & 2001 & 2002 & Air & 1 & Blanket & 0.0622 & 0.094 & 0 & 0 & 0 \\
\hline 3 & 2001 & 2003 & Air & 1 & Blanket & 0.0697 & 0.106 & 0 & 0 & 0 \\
\hline 4 & 2001 & 2004 & Air & 1 & Blanket & 0.0871 & 0.132 & 0 & 0 & 0 \\
\hline 5 & 2001 & 2005 & Air & 1 & Blanket & 0.1763 & 0.267 & 0 & 0 & 0 \\
\hline 6 & 2001 & 2006 & Air & 1 & Blanket & 0.1146 & 0.174 & 0 & 0 & 0 \\
\hline 7 & 2001 & 2007 & Air & 1 & Blanket & 0.1250 & 0.189 & 0 & 0 & 0 \\
\hline 8 & 2001 & 2008 & Air & 1 & Blanket & 0.0414 & 0.063 & 0 & 0 & 0 \\
\hline 9 & 2001 & 2002 & Multi & 2 & Blanket & 0.0058 & 0.067 & 0 & 0 & 0 \\
\hline 10 & 2001 & 2005 & Sea & 2 & Blanket & 0.0007 & 0.005 & 0 & 0 & 0 \\
\hline 11 & 2001 & 2007 & Sea & 2 & Blanket & 0.0007 & 0.005 & 0 & 0 & 0 \\
\hline 12 & 2001 & 2003 & Road & 1 & Blanket & 0.0058 & 0.071 & 0 & 0 & 0 \\
\hline 13 & 2001 & 2004 & Road & 1 & Blanket & 0.0086 & 0.105 & 0 & 0 & 0 \\
\hline 14 & 2001 & 2006 & Road & 1 & Blanket & 0.0111 & 0.136 & 0 & 0 & 0 \\
\hline 15 & 2001 & 2008 & Road & 1 & Blanket & 0.0045 & 0.056 & 0 & 0 & 0 \\
\hline
\end{tabular}

\section{Appendix 2: Experimental plan lexicographic orders}

\begin{tabular}{lllll}
\hline Order & $\mathrm{LO}^{0}$ & $\mathrm{LO}^{1}$ & $\mathrm{LO}^{2}$ & $\mathrm{LO}^{3}$ \\
\hline A (example) & Effectiveness & Economic & Social & Environmental \\
$\mathrm{B}$ & Effectiveness & Economic & Environmental & Social \\
$\mathrm{C}$ & Effectiveness & Social & Economic & Environmental \\
$\mathrm{D}$ & Effectiveness & Social & Environmental & Economic \\
$\mathrm{E}$ & Effectiveness & Environmental & Economic & Social \\
$\mathrm{F}$ & Effectiveness & Environmental & Social & Economic \\
\hline
\end{tabular}




\section{References}

Abidi, H., de Leeuw, S., \& Klumpp, M. (2014). Humanitarian supply chain performance management: A systematic literature review. Supply Chain Management: An International Journal, 19(5/6), 592-608.

Absi, N., Dauzère-Pérès, S., Kedad-Sidhoum, S., Penz, B., \& Rapine, C. (2013). Discrete Optimization: Lot sizing with carbon emission constraints. European Journal of Operational Research, 227(1), 55-61.

Altay, N., \& Green, W. G. (2005). OR/MS research in disaster operations management. European Journal of Operational Research, 175(1), 475-493.

Anaya-Arenas, A. M., Renaud, J., \& Ruiz, A. (2014). Relief distribution networks: A systematic review. Annals of Operations Research, 223, 53-79.

Ashby, A., Leat, M., \& Hudson-Smith, M. (2012). Making connections: A review of supply chain management and sustainability literature. Supply Chain Management: An International Journal, 17(5), 497-516.

Balcik, B., \& Beamon, B. M. (2008). Facility location in humanitarian relief. International Journal of Logistics Research and Applications, 11(2), 101-121.

Balcik, B., Beamon, B. M., Krejci, C. C., Muramatsu, K. M., \& Ramirez, M. (2010). Coordination in humanitarian relief chains: Practices, challenges and opportunities. International Journal of Production Economics, 126(1), 22-34.

Balcik, B., Beamon, B. M., \& Smilowitz, K. (2008). Last mile distribution in humanitarian relief. Journal of Intelligent Transportation Systems, 12(2), 51-63.

Barbarosoğlu, G., \& Arda, Y. (2004). A two-stage stochastic programming framework for transportation planning in disaster response. Journal of the Operational Research Society, 55(1), 43-53.

Baumann, E. (2011). Modèles d'évaluation des performances économique, environnementale et sociale dans les chaînes logistiques (Phd thesis). INSA de Lyon.

Beamon, B. M., \& Kotleba, S. A. (2006). Inventory modelling for complex emergencies in humanitarian relief operations. International Journal of Logistics Research and Applications, 9(1), 1-18.

Beske, P., \& Seuring, S. (2014). Putting sustainability into supply chain management. Supply Chain Management: An International Journal, 19(3), 322-331.

Blecken, A. (2010). Supply chain process modelling for humanitarian organizations. International Journal of Physical Distribution \& Logistics Management, 40(8/9), 675-692.

Bradley, S. P., Hax, A. C., \& Magnanti, T. L. (1977). Applied mathematical programming. Reading, MA: Addison-Wesley Publishing Company.

Branke, J. (Ed.). (2008). Multiobjective optimization: Interactive and evolutionary approaches. Berlin: Springer.

Brundtland, G. H. (1987). Report of the World Commission on environment and development: Our common future. Oslo: United Nations.

Cao, C., Li, C., Yang, Q., Liu, Y., \& Qu, T. S. (2018). A novel multi-objective programming model of relief distribution for sustainable disaster supply chain in large-scale natural disasters. Journal of Cleaner Production, 174, 1422-1435.

Carter, C. R., \& Easton, P. L. (2011). Sustainable supply chain management: Evolution and future directions. International Journal of Physical Distribution \& Logistics Management, 41(1), 46-62.

Carter, C. R., \& Rogers, D. S. (2008). A framework of sustainable supply chain management: Moving toward new theory. International Journal of Physical Distribution \& Logistics Management, 38(5), 360-387.

Charles, A., \& Lauras, M. (2011). An enterprise modelling approach for better optimisation modelling: Application to the humanitarian relief chain coordination problem. OR Spectrum, 33(3), 815-841.

Charvériat, C. (2000). Natural disasters in Latin America and the Caribbean: An overview of risk. Rochester, NY: Social Science Research Network.

Chopra, S., \& Meindl, P. (2004). Supply chain management: Strategy, planning, and operation. Englewood Cliffs, NJ: Pearson, Prentice-Hall.

Christopher, M. (1992). Logistics and supply chain management. London: Pitman Publishing.

Cosimato, S., \& Troisi, O. (2015). Green supply chain management: Practices and tools for logistics competitiveness and sustainability. The DHL case study. The TQM Journal, 27(2), 256-276.

D’Amours, S., Rönnqvist, M., \& Weintraub, A. (2008). Using operational research for supply chain planning in the forest products industry and paper industry. Information Systems and Operational Research, 46, 265-281.

D'Haene, C., Verlinde, S., \& Macharis, C. (2015). Measuring while moving (humanitarian supply chain performance measurement-Status of research and current practice. Journal of Humanitarian Logistics and Supply Chain management, 5(2), 146-161.

Davis, L. B., Samanlioglu, F., Qu, X., \& Root, S. (2013). Inventory planning and coordination in disaster relief efforts. International Journal of Production Economics, 141, 561-573. 
Day, J. M., Melnyk, S. A., Larson, P. D., Davis, E. W., \& Whybark, D. C. (2012). Humanitarian and disaster relief supply chain: A matter of life and death. Journal of Supply Chain Management, 48(2), 21-36.

Dubey, R., \& Gunasekaran, A. (2016). The sustainable humanitarian supply chain design: Agility, adaptability and alignment. International Journal of Logistics: Research and Applications, 19(1), 62-82.

Dubey, R., Gunasekaran, A., Childe, S. J., Papadopoulos, T., \& Fosso-Wamba, S. (2017a). World class sustainable supply chain management: Critical review and further research directions. The International Journal of Logistics Management, 28(2), 332-362.

Dubey, R., Gunasekaran, A., Childe, S. J., Papadopoulos, T., Hazen, B., Giannakis, M., et al. (2017b). Examining the effect of external pressures and organizational culture on shaping performance measurement systems (PMS) for sustainability benchmarking: Some empirical findings. International Journal of Production Economics, 193, 63-76.

Dubey, R., Gunasekaran, A., \& Papadopoulos, T. (2017c). Green supply chain management: Theoretical framework and further research directions. Benchmarking: An International Journal, 24(1), 184-218.

Elkington, J. (1998). Accounting for the triple bottom line. Measuring Business Excellence, 2(3), 18-22.

FAO. (2006). Food aid's intended and unintended consequences (ESA Working Paper 06-05). Rome.

Filho, W. L. (2000). Dealing with misconceptions on the concept of sustainability. International Journal of Sustainability in Higher Education, 1(1), 9-19.

Fleischmann, B., Meyr, H., \& Wagner, M. (2005). Advanced planning. In H. Stadtler \& C. Kilger (Eds.), Supply chain management and advanced planning (pp. 81-106). Springer, Berlin.

Galindo, G., \& Batta, R. (2013). Review of recent developments in OR/MS research in disaster operations management. European Journal of Operational Research, 230(2), 201-211.

Gopalakrishnan, K., Yusuf, Y. Y., Musa, A., Abubakar, T., \& Ambursa, H. M. (2012). Sustainable supply chain management: A case study of British Aerospace (BAe) systems. International Journal of Production Economics, 140, 193-203.

Gralla, E., Goentzal, J., \& Fine, C. (2014). Assessing trade-offs among multiple objectives for humanitarian aid delivery using expert preferences. Production and Operations Management, 23(6), 978-989.

Gralla, E., Goentzal, J., \& Fine, C. (2016). Problem formulation and solution mechanisms: A behavioral study of humanitarian transportation planning. Production and Operations Management, 25(1), 22-359.

Green, K. W., Zelbst, P. J., Meacham, J., \& Bhadauria, V. S. (2012). Green supply chain management practices: Impact on performance. Supply Chain Management: An International Journal, 17(3), 290-305.

Gualandris, J., Klassen, R. D., Vachon, S., \& Kalchschmidt, M. (2015). Sustainable evaluation and verification in supply chains: Aligning andleveraging accountability to stakeholders. Journal of Operations Management, 38, 1-13.

Gunasekaran, A., Dubey, R., \& Singh, S. P. (2016). Flexible sustainable supply chain network design: Current trends, opportunities and future. Global Journal of Flexible Systems Management, 17(2), 109-112.

Haavisto, I., \& Goentzal, J. (2015). Measuring humanitarian supply chain performance in a multi-goal context. Journal of Humanitarian Logistics and Supply Chain management, 5(3), 300-324.

Haavisto, I., \& Kovács, G. (2014). Perspectives on sustainability in humanitarian supply chains. Disaster Prevention and Management, 23(5), 610-631.

Hart, S. L. (1997). Beyond greening-Strategies for a Sustainable World. Harvard Business Review, 75(1), 66-76.

Hausladen, I., \& Haas, A. (2013). Considering sustainability in the context of humanitarian logistics. In B. Hellingrath, D. Link, \& A. Widera (Eds.), Managing humanitarian supply chains (pp. 314-329). Hamburg: DVV Media Group GmbH.

Hemming, C., Pugh, S., Williams, G., \& Blackburn, D. (2004). Strategies for sustainable development: Use of a benchmarking tool to understand relative strengths and weaknesses and identify best practice. Corporate Social Responsibility and Environmental Management, 11, 103-113.

Hervani, A. A., Helms, M. M., \& Sarkis, J. (2005). Performance measurement for green supply chain management. Benchmarking: An International Journal, 12(4), 330-353.

Holguín-Veras, J., Pérez, N., Jaller, M., Van Wassenhove, L. N., \& Aros-Vera, F. (2013). On the appropriate objective function for post-disaster humanitarian logistics models. Journal of Operations Management, 31(5), 262-280.

Huang, M., Smilowitz, K., \& Balcik, B. (2012). Models for relief routing: Equity, efficiency and efficacy. Transportation Research Part E: Logistics and Transportation Review, 48(1), 2-18.

Huang, Z., Wei, Y.-M., Wang, K., \& Liao, H. (2017). Energy economics and climate policy modeling. Annals of Operations Research, 255, 1-7.

IFRC. (2010). IFRC strategy 2020. IFRC. Accessed 29 July 2015.

Jabbour, C. J. C., de Sousa, Lopes, Jabbour, A. B., Govindan, K., Pignatti de Freitas, T., Soubihia, D. F., et al. (2016). Barriers to the adoption of green operational practices at Brazilian companies: Effects on green and operational performance. International Journal of Production Research, 54(10), 3042-3058. 
Jabbour, C. J., Sobreiro, V. A., Lopes de Sousa Jabbour, A. B., de Souza Campos, L. M., Mariano, E. B., \& Renwick, D. W. S. (2017). An analysis of the literature on humanitarian logistics and supply chain management: Paving the way for future studies. Annals of Operations Research. https://doi.org/10.1007/ s10479-017-2536-x.

Jaggernath, R., \& Khan, Z. (2015). Green supply chain management. World Journal of Entrepreneurship, Management and Sustainable development, 11(1), 37-47.

Jahre, M. (2008). The organizational change of logistics in International Federation of the Red Cross and Red Crescent Societies (Case Study). HUMLOG-NET Project.

Jahre, M., \& Heigh, I. (2008). Does the current constraints in funding promote failure in humanitarian supply chains? Supply Chain Forum: An International Journal, 9(2), 44-55.

Kauder, S., \& Meyr, H. (2009). Strategic network planning for an international automotive manufacturer: Balancing flexibility and economic efficiency. OR Spectrum, 31, 507-532.

Kiewiet, D. J., \& Vos, J. F. J. (2007). Organizational sustainability: A case for formulating a taylor-made definition. Journal of Environmental Assessment Policy and Management, 9(1), 1-18.

Kleindorfer, P. R., Singhal, K., \& van Wassenhove, L. N. (2005). Sustainable operations management. Production and Operations Management, 14(4), 482-492.

Klumpp, M., De Leeuw, S., Regattieri, A., \& de Souza, R. (2015). Humanitarian logistics and sustainability. Berlin: Springer.

Kovács, G., \& Spens, K. M. (2011). Trends and developments in humanitarian logistics-A gap analysis. International Journal of Physical Distribution \& Logistics Management, 41(1), 32-45.

Kunz, N., \& Gold, S. (2017). Sustainable humanitarian supply chain management-Exploring new theory. International Journal of Logistics: Research and Applications, 20(2), 85-104.

Laguna Salvadó, L., Lauras, M., \& Comes, T. (2017). Sustainable performance measurement for humanitarian supply chain operations. In Proceedings of the international conference on information systems for crisis response and management (pp. 775-783). Presented at the ISCRAM 2017, Albi.

Maas, K., \& Liket, K. (2011). Social impact measurement: classification of methods. In R. L. Burritt, S. Schaltegger, M. Bennett, T. Pohjola \& M. Csutora (Eds.), Environmental management accounting and supply chain management (pp. 171-202). Springer, Dordrecht.

Markley, M. J., \& Davis, L. (2007). Exploring future competitive advantage through sustainable supply chains. International Journal of Physical Distribution \& Logistics Management, 37(9), 763-774.

Maryniak, A. (2017). Competitive instruments preferred by customers versus the level of pro-environmental activities in a supply chain. LogForum, 13(2), 159-169.

Medina-Borja, A., \& Triantis, K. (2014). Modeling social services performance: A four-stage DEA approach to evaluate fundraising efficiency, capacity building, service quality, and effectiveness in the nonprofit sector. Annals of Operations Research, 221, 285-307.

Mete, H. O., \& Zabinsky, Z. B. (2010). Stochastic optimization of medical supply location and distribution in disaster management. International Journal of Production Economics, 126, 76-84.

Neely, A., Gregory, M., \& Platts, K. (1995). Performance measurement system design: A literature review and research agenda. International Journal of Operations and Production Management, 15, 80-116.

Noham, R., \& Tzur, M. (2018). Designing humanitarian supply chains by incorporating actual post-disaster decisions. European Journal of Operational Research, 265, 1064-1077.

Oloruntoba, R. (2010). An analysis of the Cyclone Larry emergency relief chain: Some key success factors. International Journal of Production Economics, 126, 85-101.

Ozbay, K., \& Ozguven, E. (2007). Stochastic humanitarian inventory control model for disaster planning. Transportation Research Record, 2022, 63-75.

Özdamar, L., Ekinci, E., \& Küçükyazici, B. (2004). Emergency logistics planning in natural disasters. Annals of Operations Research, 129(1), 217-245.

Paulraj, A., Chen, I. J., \& Blome, C. (2017). Motives and performance outcomes of sustainable supply chain management practices: A multiple-theoretical perspective. Journal of Business Ethics, 145, 239-258.

Pedraza-Martinez, A. J., Stapleton, O., \& Van Wassenhove, L. N. (2013). On the use of evidence in humanitarian logistics research. Disasters, 37, S51-S67.

Pojasek, R. B. (2012). Understanding sustainability: An organizational perspective. Environmental Quality Management, 21(3), 93-100.

Presley, A., Meade, L., \& Sarkis, J. (2007). A strategic sustainability justification methodology for organizational decisions: A reverse logistics illustration. International Journal of Production Research, 45(18-19), 4595-4620.

Rastegar, N., \& Khorram, E. (2015). Relaxation of constraints in lexicographic multiobjective programming problems. Optimization: A Journal of Mathematical Programming and Operations Research, 64(10), 2111-2129. 
Rentmeesters, M. J., Tsai, W. K., \& Lin, K.-J. (1996). A theory of lexicographic multi-criteria optimization. In Proceedings of the second IEEE international conference on engineering of complex computer systems, 1996 (pp. 76-79).

Richardson, D. A., De Leeuw, S., \& Dullaert, W. (2016). Factors affecting global inventory locations in humanitarian operations-a Delphi study. Journal of Business Logistics, 37(1), 59-74.

Robins, F. (2006). The challenge of TBL: A responsibility to whom? Business and Society Review, 111(1), $1-14$.

Rottkemper, B., Fischer, K., Blecken, A., \& Danne, C. (2011). Inventory relocation for overlapping disaster settings in humanitarian operations. OR Spectrum, 33, 721-749.

Rudberg, M., \& Thulin, J. (2009). Centralised supply chain master planning employing advanced planning systems. Production Planning \& Control, 20(2), 158-167.

Santarelli, G., Abidi, H., Klumpp, A. R., \& Regattieri, A. (2015). Humanitarian supply chains and performance measurement schemes in practice. International Journal of Productivity and Performance Measurement, 64(6), 784-810.

Sarkis, J., Zhu, Q., \& Lai, K-h. (2011). An organizational theoretic review of green supply chain management literature. International Journal of Production Economics, 130, 1-15.

Schrettle, S., Hinz, A., Scherrer-Rathje, M., \& Friedli, T. (2014). Turning sustainability into action: Explaining firms sustainability efforts and their impact on firm performance. International Journal of Production Economics, 147, 73-84.

Seuring, S., \& Müller, M. (2008). From a literature review to a conceptual framework for sustainable supply chain management. Journal of Cleaner Production, 16(15), 1699-1710.

Sherali, H. D. (1982). Equivalent weights for lexicographic multi-objective programs: Characterizations and computations. European Journal of Operational Research, 11(4), 367-379.

Singh, A., \& Trivedi, A. (2016). Sustainable green supply chain management: Trends and current practices. Competitiveness Review, 26(3), 265-288.

Stadtler, H. (2005). Supply chain management and advanced planning-Basics, overview and challenges. European Journal of Operational Research, 163(3), 575-588.

Stadtler, H., \& Kilger, C. (Eds.). (2005). Supply chain management and advanced planning: Concepts, models, software and case studies (3rd ed.). Berlin: Springer.

Tatham, P. H., \& Pettit, S. J. (2010). Transforming humanitarian logistics: The journey to supply chain network management. International Journal of Physical Distribution \& Logistics Management, 40(8/9), 609-622.

Taticchi, P., Garengo, P., Nudurupati, S. S., Tonelli, F., \& Pasqualino, R. (2015). A review of decision-support tools and performance management and sustainable supply chain management. International Journal of Production Research, 53(21), 6473-6494.

Thomas, A. (2003). Humanitarian logistics: Enabling disaster response. San Francisco: Fritz Institute. http:/ /www.fritzinstitute.org/pdfs/whitepaper/enablingdisasterresponse.pdf. Accessed 10 Nov 2016.

Tzur, M. (2016). The humanitarian pickup and distribution problem. Presented at the EuroHope miniconference, Hamburg. March 5.

Ülkü, M. A., Bell, K. M., \& Wilson, S. G. (2015). Modeling the impact of donor behavior on humanitarian aid operations. Annals of Operations Research, 230, 153-168.

UN OCHA. (2014). Global Humanitarian Overview (Status Report). https:/www.unocha.org/sites/unocha/ files/Global\%20Humanitarian\%20Overview\%20Final\%2022\%20Aug\%202014.pdf. Accessed 25 Feb 2015.

United Nations. (2016a). The Sustainable Development Goals Report 2016. (L. Jensen, Ed.). New York: United Nations.

United Nations. (2016b). One humanity: shared responsibility_Report of the Secretary-General for the World Humanitarian Summit.

Van Wassenhove, L. N. (2006). Humanitarian aid logistics: Supply chain management in high gear. Journal of the Operational Research Society, 57(5), 475-489.

Vanajakumari, M., Kumar, S., \& Gupta, S. (2016). An integrated logistics model for predictable disasters. Production and Operations Management, 25(5), 791-811.

Vargas Florez, J., Lauras, M., Okongwu, U., \& Dupont, L. (2015). A decision support system for robust humanitarian facility location. Engineering Applications of Artificial Intelligence, 46, 326-335.

Vega-Mejía, C. A., Montoya-Torres, J. R., \& Islam, S. M. N. (2017). Consideration of triple bottom line objectives for sustainability in the optimization of vehicle routing and loading operations: A systematic literature review. Annals of Operations Research. https://doi.org/10.1007/s10479-017-2723-9.

Vinck, P. (Ed.). (2013). World disasters report 2013: Focus on technology and the future of humanitarian intervention. Geneva: IFRC.

WFP. (2017). Cash-based transfers for delivering food assistance. World Food Programme. www.wfp.org/ content/2017-cash-based-transfers-fact-sheet. Accessed 12 July 2017. 
Widera, A., Dietrich, H.-A., Hellingrath, B., \& Becker, J. (2013). Understanding humanitarian supply chains-Developing an integrated process analysis toolkit. In 10th International ISCRAM Conference. Presented at the Information Systems for Crisis Response and Management, Baden-Baden.

Wilson, M. (2003). Corporate sustainability: What is it and where does it come from? Ivey Business Journal, $67(6), 1-5$.

Wray, K. H., Zilberstein, S., \& Mouaddib, A.-I. (2015). Multi-objective MDPs with conditional lexicographic reward preferences. In Twenty-ninth AAAI conference on artificial intelligence (pp. 3418-3424). Presented at the AAAI, Austin, Texas, USA: AAAI Press.

Yadav, D., \& Barve, A. (2016). Modeling oost-disaster challenges of humanitarian supply chains: A TISM approach. Global Journal of Flexible Systems Management, 17(3), 321-340.

Yang, F., Yuan, Q., Du, S., \& Liang, L. (2016). Reserving relief supplies for earthquake: A multi-attribute decision making of China Red Cross. Annals of Operations Research, 247, 759-785.

Ye, Y., \& Liu, N. (2013). Humanitarian logistics planning for natural disaster response with Bayesian information updates. Journal of Industrial and Management Optimization, 10(3), 665-689. 